\title{
Neutronics and Fuel Performance Evaluation of Accident Tolerant Fuel under Normal Operation Conditions
}

INL Summer 2014

Xu Wu

Piyush Sabharwall

Jason Hales

University of Illinois, Urbana-Champaign Tomasz Kozlowski

July 2014

The INL is a U.S. Department of Energy National Laboratory operated by Battelle Energy Alliance 


\section{DISCLAIMER}

This information was prepared as an account of work sponsored by an agency of the U.S. Government. Neither the U.S. Government nor any agency thereof, nor any of their employees, makes any warranty, expressed or implied, or assumes any legal liability or responsibility for the accuracy, completeness, or usefulness, of any information, apparatus, product, or process disclosed, or represents that its use would not infringe privately owned rights. References herein to any specific commercial product, process, or service by trade name, trade mark, manufacturer, or otherwise, does not necessarily constitute or imply its endorsement, recommendation, or favoring by the U.S. Government or any agency thereof. The views and opinions of authors expressed herein do not necessarily state or reflect those of the U.S. Government or any agency thereof. 
INL/EXT-14-32591

Revision 1

\title{
Neutronics and Fuel Performance Evaluation of Accident Tolerant Fuel under Normal Operation Conditions
}

\author{
INL Summer 2014 \\ Xu Wu , Piyush Sabharwall, Jason Hales, \\ University of Illinois, Urbana-Champaign \\ Tomasz Kozlowski
}

July 2014

Idaho National Laboratory Idaho Falls, Idaho 83415

http://www.inl.gov

Prepared for the

U.S. Department of Energy

Office of Nuclear Energy

Under DOE Idaho Operations Office

Contract DE-AC07-05ID14517 


\section{ABSTRACT}

This report details the analysis of neutronics and fuel performance for enhanced accident tolerance fuel, with Monte Carlo reactor physics code Serpent and INL's fuel performance code BISON, respectively. The purpose is to evaluate two of the most promising candidate materials, FeCrAl and Silicon Carbide ( $\mathrm{SiC}$ ), as the fuel cladding under normal operating conditions.

Substantial neutron penalty is identified when FeCrAl is used as monolithic cladding for current oxide fuel. From the reactor physics standpoint, application of the $\mathrm{FeCrAl}$ alloy as a coating layer on the surface of zircaloy cladding is possible without increasing fuel enrichment. Meanwhile, $\mathrm{SiC}$ brings extra reactivity and the neutron penalty is of no concern.

Application of either $\mathrm{FeCrAl}$ or $\mathrm{SiC}$ could be favorable from the fuel performance standpoint. Detailed comparison between monolithic cladding and hybrid cladding (cladding + coating) is discussed. Hybrid cladding is more practical based on the economics evaluation during the transition from current $\mathrm{UO}_{2}$ /zircaloy to the Accident Tolerant Fuel (ATF) system. However, a few issues remain to be resolved, such as the creep behavior of FeCrAl, coating spallation, inter-diffusion with zirconium, etc. For $\mathrm{SiC}$, its high thermal conductivity, excellent creep resistance, low thermal neutron absorption cross-section, and irradiation stability (minimal swelling) make it an excellent candidate material for future nuclear fuel/cladding systems. 


\section{CONTENTS}

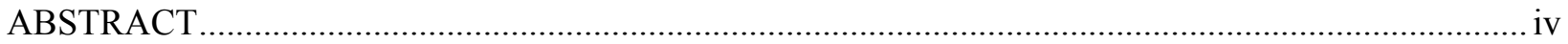

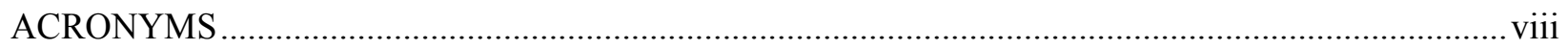

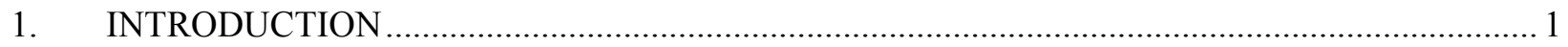

2. THERMAL-PHYSICAL PROPERTIES OF CANDIDATE MATERIALS …............................. 2

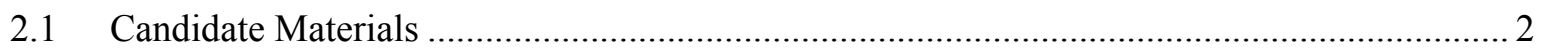

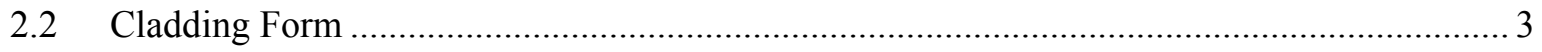

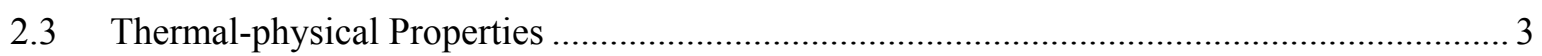

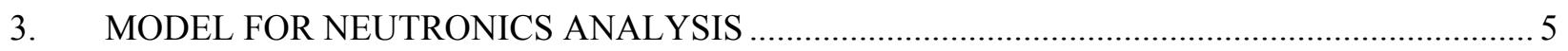

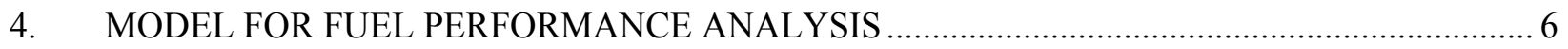

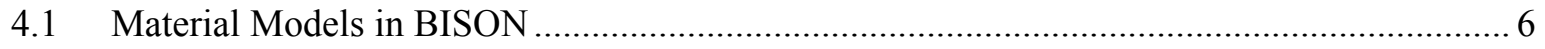

4.2 LWR Fuel Pin Model in BISON ....................................................................................... 7

4.3 Mesh for Coating and Monolithic Cladding Cases …......................................................... 7

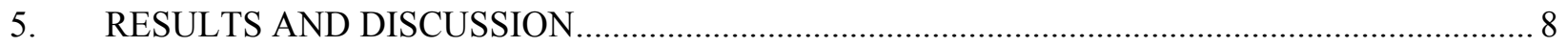

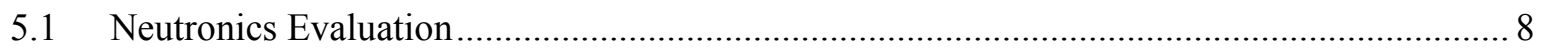

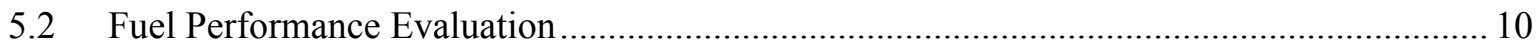

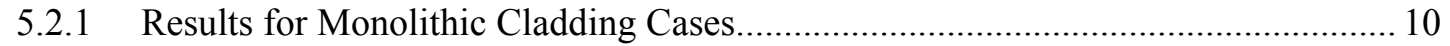

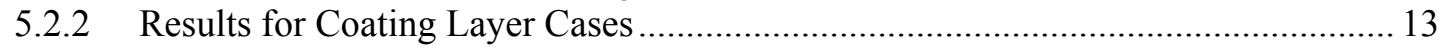

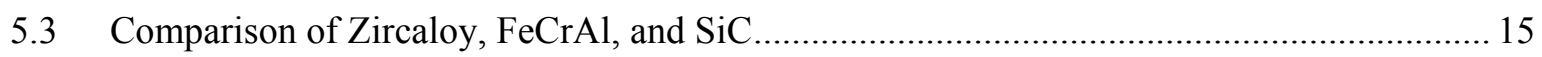

5.4 Comparison of Monolithic Cladding and Coating .......................................................... 15

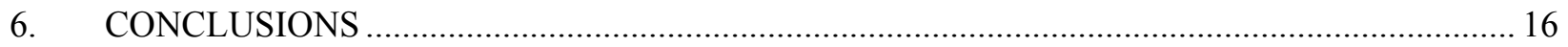

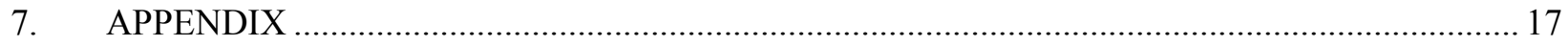

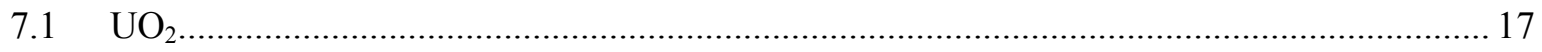

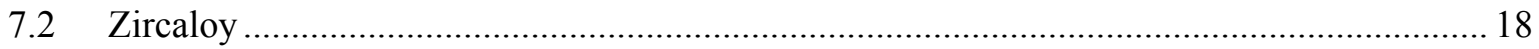

7.3 $\mathrm{FeCrAl}$

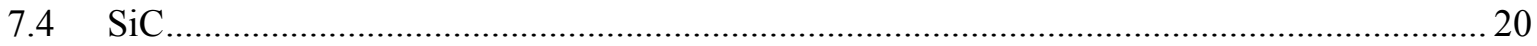

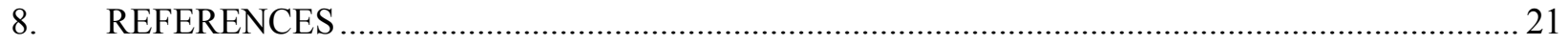

\section{FIGURES}

Figure 1. Material density (left), thermal conductivity (right).......................................................... 4

Figure 2. Specific heat capacity (left), Poisson's ratio (right)............................................................ 4

Figure 3. Thermal expansion (left), Young's modulus (right)................................................................... 4

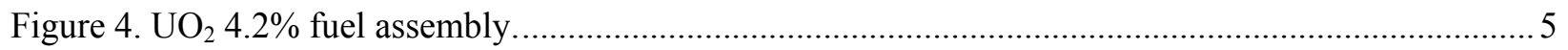




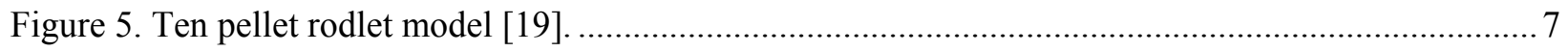

Figure 6. Mesh for monolithic cladding (left) and coating (right) cases................................................ 8

Figure 7. Comparison of $\mathrm{k}_{\mathrm{eff}}$ versus burnup for PWR single assembly, with various cladding

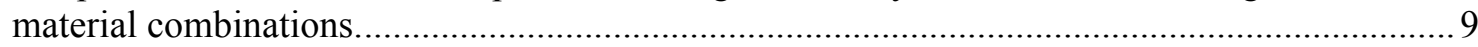

Figure 8. (Left) Fission gas released, (right) plenum pressure. ........................................................... 11

Figure 9. (Left) Average interior temperature, (right) average cladding temperature. ............................ 11

Figure 10. (Left) Temperature distribution over the fuel centerline at the end of simulation,

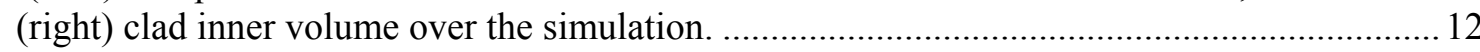

Figure 11. Plot over the horizontal center line of the fifth fuel pellet from bottom at the end of simulation (left), temperature distribution, (right) radial displacement distribution.

Figure 12. Plot of gap sizes for two nodes on fuel pellet surface, (left) at height of $0.012 \mathrm{~m}$, (right) at height of $0.07 \mathrm{~m}$......

Figure 13. (Left) Fission gas released, (right) plenum pressure. .......................................................... 13

Figure 14. (Left) Average interior temperature, (right) average cladding temperature. .......................... 13

Figure 15. (Left) Temperature distribution over the fuel centerline at the end of simulation, (right) clad inner volume over the simulation.

Figure 16. Plot over the horizontal center line of the fifth fuel pellet from bottom at the end of simulation, (left) temperature distribution, (right) radial displacement distribution.

Figure 17. Plot of gap sizes for two nodes on fuel pellet surface, (left): at height of $0.012 \mathrm{~m}$, (right) at height of $0.07 \mathrm{~m}$ 14

\section{TABLES}

Table 1. Material composition. 6

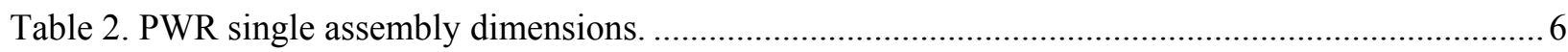

Table 3. Comparison of effective multiplication factor $\mathrm{k}_{\mathrm{eff}}$ for PWR single assembly with various

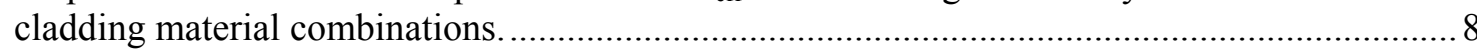

Table 4. Comparison of effective multiplication factor keff for PWR single assembly with various

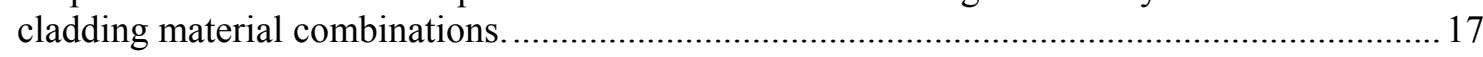

Table 5. Dependence of Zircaloy density and specific heat capacity on temperature for Zircaloy. 


\section{ACRONYMS}

APMT Commercial oxide dispersion strengthened (ODS) FeCrAl alloy

ATF Accident Tolerant Fuels

BDB Beyond Design-Basis

DB Design-Basis

DOE Department of Energy

FCM Fully Ceramic Micro-encapsulated

HTGR High-Temperature Gas-Cooled

IFBA Integral Fuel Burnable Absorber

INL Idaho National Laboratory

IRP Integrated Research Project

LOCA Loss-of-Coolant Accident

LTSBO Long-Term Station Blackout

LWR Light Water Reactor

MOOSE Multiphysics Object Oriented Simulation Environment

MOX Mixed Oxide

NEUP Nuclear Energy University Program

ODS Oxide Dispersion Strengthened

ORNL Oak Ridge National Laboratory

PCMI Pellet-Cladding Mechanical Interaction

PWR Pressurized Water Reactor

RIA Reactivity Insertion Accident

SiC Silicon Carbide

SS Stainless Steel

STSBO Short-Term Station Blackout

TRISO Tristructural Isotropic

WABA Wet Annular Burnable Absorber 


\title{
Neutronics and Fuel Performance Evaluation of Accident Tolerant Fuel under Normal Operation Conditions
}

\author{
1. INTRODUCTION
}

Following the Fukushima Daiichi nuclear disaster in 2011, the emphasis for nuclear fuel R\&D activities has shifted from fuel reliability and waste minimization to enhancing the accident-tolerance of Light Water Reactor (LWR) fuels. By definition, enhanced Accident Tolerant Fuels (ATFs) can tolerate loss of active cooling in the core for a considerably longer time period (depending on the LWR system and accident scenario) compared with the standard $\mathrm{UO}_{2}$-zircaloy system currently used [1]. Furthermore, the ATF fuel/cladding system should maintain or improve the fuel performance during normal operations, operational transients, as well as design-basis (DB) and beyond design-basis (BDB) events [1].

Three potential approaches are proposed for the development of fuel/cladding systems that have enhanced accident tolerance [2] [3].

1. Improve or replace the monolithic ceramic oxide fuel

2. Modify current zircaloy cladding to achieve improved oxidation resistance, including application of coating layer

3. Replace zircaloy cladding with an alternative oxidation-resistant high-performance cladding.

The evaluation of ATF should involve the assessment of its performance under normal operations and accident scenarios. One of the potential approaches that has been extensively explored is improving the oxidation resistance of the cladding.

Currently, the heat transfer coefficient between the zircaloy cladding exterior surface and the coolant is on the order of $1 \mathrm{~W} /\left(\mathrm{cm}^{2} \mathrm{~K}\right)$, under normal operating conditions [4]. However, under accident conditions, when the fuel rods are exposed to a slow flowing or stagnant steam, this parameter could decrease by four orders of magnitude, resulting in poor fuel cladding-to-coolant heat convection. Consequently, decay heat will drive up the fuel temperature, and a rapid exothermic zircaloy oxidation reaction will happen in the high-temperature steam environment, accompanied by significant hydrogen production. Zirconium cladding oxidation in high-temperature steam environments with poor heat transfer to the gaseous phase is characteristic of a self-catalytic process (at temperature higher than $1200^{\circ} \mathrm{C}$ ) [4]. The enthalpy production (-586 kJ/mole for zirconium) from oxidation reaction, along with the decay heat, will keep increasing the fuel temperature to the melting point. Therefore, cladding with improved oxidation resistance and less heat/hydrogen generation is expected to achieve larger margins of safety against severe accident scenarios.

A slow-growing alumina surface oxide formation during steam oxidation of APMT (a commercial oxide dispersion strengthened [ODS] FeCrAl alloy) alloy was identified at Oak Ridge National Laboratory (ORNL) [5]. This indicates a promising choice for nuclear fuel cladding under high temperature accident conditions. Post-quench ductility studies were conducted with zircaloy-4, stainless steel- (SS) 317, SS-347, and APMT alloy cladding samples at temperatures of $1200^{\circ} \mathrm{C}$, followed by cooling to $800^{\circ} \mathrm{C}$ and then a water quench at room temperature to simulate the design basis Loss-Of-Coolant Accident (LOCA) conditions and beyond [6]. Among all the materials examined, the APMT sample showed the slowest oxidation rate. Also, after oxidation up to 4 hours, no ductility decrease was observed for the post-quenched APMT samples.

Iron-based alloys, like standard commercial austenitic SS-310: $\mathrm{Fe}-25 \mathrm{Cr}-20 \mathrm{Ni}-2 \mathrm{Mn}$, as well as Kanthal APMT ferritic alloy: $\mathrm{Fe}-22 \mathrm{Cr}-5 \mathrm{Al}-3 \mathrm{Mo}$, were reexamined for their potential application as nuclear fuel cladding to replace zirconium alloys [4]. Two standard DB scenarios were investigated: 
LOCAs and Reactivity Insertion Accidents (RIAs). The magnitude of the parabolic oxidation rate constant for APMT and SS-310 were found to be roughly two to three orders of magnitude lower than what is observed for zirconium alloys.

Several candidate cladding materials (such as SS-310, FeCrAl, and SiC) were investigated at ORNL, which specifically involves oxidation resistance to steam or steam- $\mathrm{H}_{2}$ environment at over $1200^{\circ} \mathrm{C}$ for shorter times [7]. They were demonstrated to have significantly lower oxidation kinetics and hydrogen generation. The experimental work concluded the most promising alloys for severe accident tolerance are $\mathrm{FeCrAl}$ alloys with $\sim 20 \mathrm{Cr}-5 \mathrm{Al}$ and $\mathrm{Fe}-\mathrm{Cr}$ alloys with $>=25 \mathrm{Cr}$. High $\mathrm{Cr}(>=25 \%)$ ferritic steels appear to be promising candidates, but chromia-forming alloys were generally not as resistant as alumina-forming alloys or $\mathrm{SiC}$ at higher temperatures [7].

$\mathrm{SiC}$ has been proposed as a potential cladding material due to its low thermal neutron absorption cross-section, improved irradiation and oxidation resistance in air and steam up to temperatures of at least $1600^{\circ} \mathrm{C}$ [3]. A new fuel form, Fully Ceramic (which is SiC) Micro-encapsulated (FCM) matrix with tristructural isotropic (TRISO) fuel particles, was shown to have superior structural integrity [8]. The FCM concept was originally developed for high-temperature gas-cooled (HTGR) reactors in which the TRISO particles are dispersed within a graphite matrix. However, it has been adapted for use in LWR fuel elements using a $\mathrm{SiC}$ matrix [2]. A known issue with the application of $\mathrm{SiC}$ in LWR fuel is the current lack of engineering familiarity in design and application.

TRACE and MELCOR were used to evaluate the impact of new candidate fuel/cladding materials (SS310, FeCrAl, FCM/SiC) on the reactor system under DB (RIA and LOCA) and BDB (short-term and long-term station blackout [STSBO, LTSBO]) accident conditions. The use of ATFs provides an increased time margin for accident response and mitigation measures. The additional time is approximately an hour to a few hours, and can serve as valuable response time for restoring core cooling and accident mitigation. The application of these ATFs also slowed hydrogen generation [2].

The U.S. Department of Energy's (DOE) Office of Nuclear Energy has been calling for efforts to investigate enhanced ATFs for LWRs. Idaho National Laboratory (INL) and the University of Illinois are actively involved in an Integrated Research Project (IRP) supported by DOE Nuclear Energy University Programs (NEUP) [9] [10]. The goal of the IRP is to fabricate and evaluate modified LWR zircaloy cladding under normal operation conditions and off-normal scenarios. Results of the first stage, which involves the reactor system neutronics modeling with coating applied to the surface of LWR fuel cladding, is included in Wu, Kozlowski, and Heuser's 2014 conference paper [10].

Even though much experimental research and system simulation under DB and BDB conditions has been done, no detailed evaluation of the impact of advanced cladding at normal operation conditions is available in the literature. In this report, results for the second stage of IRP-ATF will be reported, which includes the fuel performance investigation and detailed simulation effort with the INL fuel performance analysis code BISON [11]. Section 2 will discuss composition, thermal-physical properties, other necessary material models such as thermal and irradiation creep, and oxidation behavior. Sections 3 and 4 provide an overview of the neutronics analysis and fuel performance analysis with candidate cladding materials. Results and discussion are presented in Section 5, followed by conclusions in Section 6.

\section{THERMAL-PHYSICAL PROPERTIES OF CANDIDATE MATERIALS 2.1 Candidate Materials}

FeCrAl alloy and SS-310 represent the two major types of oxidation-resistant alloys at high

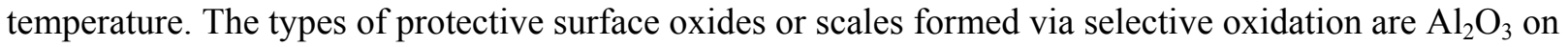
APMT and $\mathrm{Cr}_{2} \mathrm{O}_{3}$ on SS-310 [4]. However, the material composition of a standard commercial austenitic 310 stainless steel $(\mathrm{Fe}-25 \mathrm{Cr}-20 \mathrm{Ni}-2 \mathrm{Mn})$ has very high nickel concentration. The thermal neutron absorption cross-section of nickel is about twice that of iron. The parameter for iron is about 12-16 times 
higher than that of zirconium [4] [7]. Therefore, SS-310 cladding is expected to have significant neutron penalty. Meanwhile, nickel could produce radioactive cobalt via the ${ }^{58} \mathrm{Ni}(\mathrm{n}, \mathrm{p}){ }^{58} \mathrm{Co}$ reaction [4] [7]. For these reasons, SS-310 is not considered as fuel cladding in this study.

Kanthal APMT FeCrAl alloy is one example of a class of alumina-forming ferritic alloys. The material composition used is $\mathrm{Fe}$ (balance in wt. $\%$ ), $21 \% \mathrm{Cr}, 5.8 \% \mathrm{Al}, 0.7 \% \mathrm{Si}, 0.4 \% \mathrm{Mn}, 0.08 \% \mathrm{C}$. It includes ODS variants with increased creep resistance at high temperature [4].

Another candidate material studied here is $\mathrm{SiC}$. Note that, as is mentioned earlier, $\mathrm{SiC}$ is mainly intended to be used in FCM fuel as matrix. But because of its high-thermal conductivity (as will be shown in the following subsection), low-thermal neutron absorption cross-section, and excellent irradiation and oxidation resistance in air and steam up to temperatures of at least $1600^{\circ} \mathrm{C}$ [3], $\mathrm{SiC}$ is included as candidate cladding material.

\subsection{Cladding Form}

Possible forms for the application of the candidate cladding material are: (1) using it as monolithic cladding to replace zircaloy; (2) using it as a thin coating layer on the surface of zircaloy cladding.

The method proposed in the IRP-ATF project is to modify the existing zircaloy cladding. A thin coating layer (100 micron thickness) is applied to the cladding surface. When exposed to steam during temperature excursions, this coating layer is expected to shift the $\mathrm{M}+\mathrm{O} \rightarrow \mathrm{MO}$ reaction away from oxide growth to protect LWR fuel cladding [9] [10].

However, recently researchers from ORNL identified some major drawbacks for this kind of cladding/coating system [3] [4] [7] [12], which include:

1. Careful matching of the thermal expansion coefficient for coating and cladding is necessary to minimize interfacial stresses and delamination during cycling [3].

2. Diametrical compression that results from reactor pressurization makes the application of brittle ceramics problematic (generally requiring relatively thin and highly adherent coatings) [3].

3. Different volumetric and microstructural evolution between the coating and underlying cladding under neutron irradiation (e.g., anisotropic growth) can lead to coating spallation [3].

4. High-temperature oxidation protection, especially in steam, is more readily and robustly accomplished by selective oxidation of one bulk component of the alloy ( $\mathrm{Al}$ or $\mathrm{Cr}$ ) than via coatings [4].

5. $\mathrm{SiC}$ is difficult to fabricate and has lower ductility than metallic cladding. Also, the thin $\mathrm{SiO}_{2}$ layer that forms on $\mathrm{SiC}$ is known to be less protective in the presence of water vapor because of the formation of volatile hydroxides [7].

6. High-temperature inter-diffusion of $\mathrm{Fe}$ with $\mathrm{Cr}$ and $\mathrm{Ni}$ could be a significant issue [12].

However, coating application has its own advantages, such as convenience in coating regeneration. Another reason for coating would be the reduction in neutron penalty compared with monolithic cladding. Therefore, for neutronics and fuel performance analysis, both coating (hybrid) and monolithic cladding are investigated here. After comparing the results, a detailed summary of the comparisons is presented in Section 5.

\subsection{Thermal-physical Properties}

Figures 1, 2, and 3 show various thermal-physical properties used for each material considered. Most of the properties are the same as those used in Ott, Robb, and Wang's 2014 article [2], with a minor difference in $\mathrm{UO}_{2}$ thermal conductivity. Here the Fink-Lucuta model defined in Hales, et al., 2014 report [13] is used for $\mathrm{UO}_{2}$ thermal conductivity. Note that all the parameters shown in the three figures are at 
zero burnup. In BISON, while the parameters for $\mathrm{UO}_{2}$ and zircaloy have dependence on both temperature and either burnup or neutron flux and fluence, those for $\mathrm{FeCrAl}$ and $\mathrm{SiC}$ have only dependence on temperature. In addition, thermal conductivity values shown do not consider the effects of neutron irradiation. It is observed the thermal conductivity of $\mathrm{SiC}$ is reduced by $>30 \%$ after irradiation [2]. Tabulated material properties used in the report are provided in the appendix.
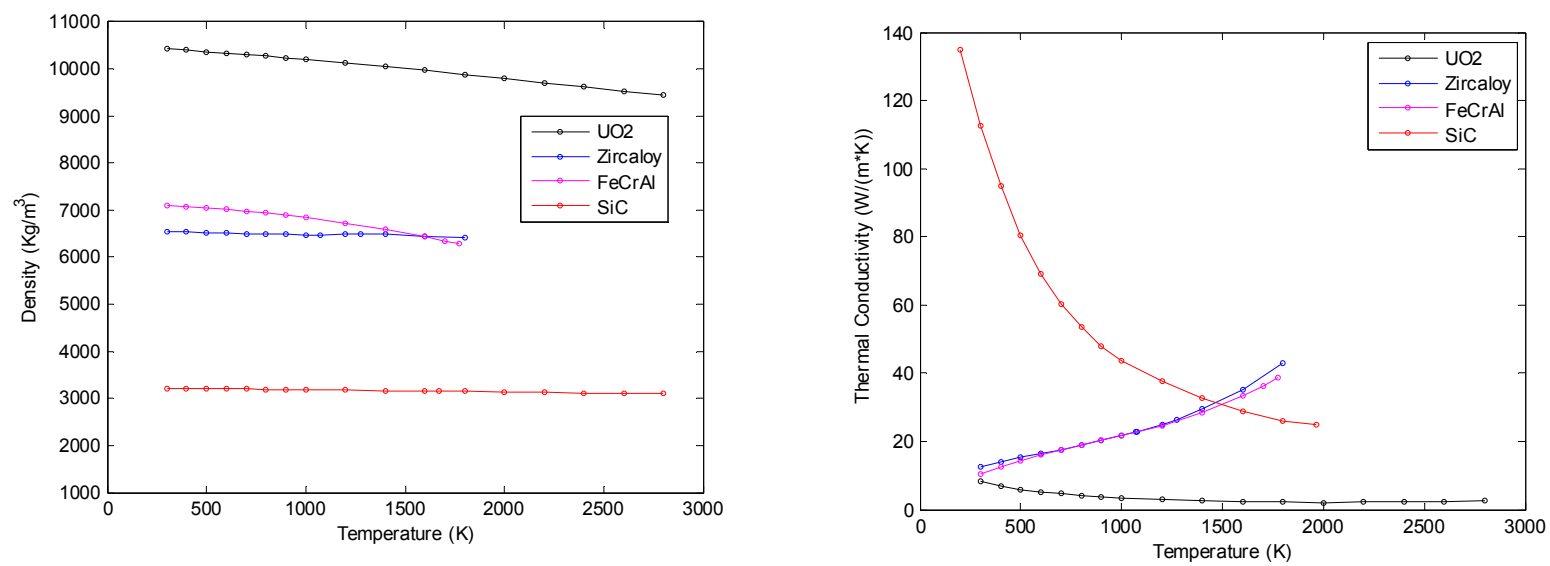

Figure 1. Material density (left), thermal conductivity (right).
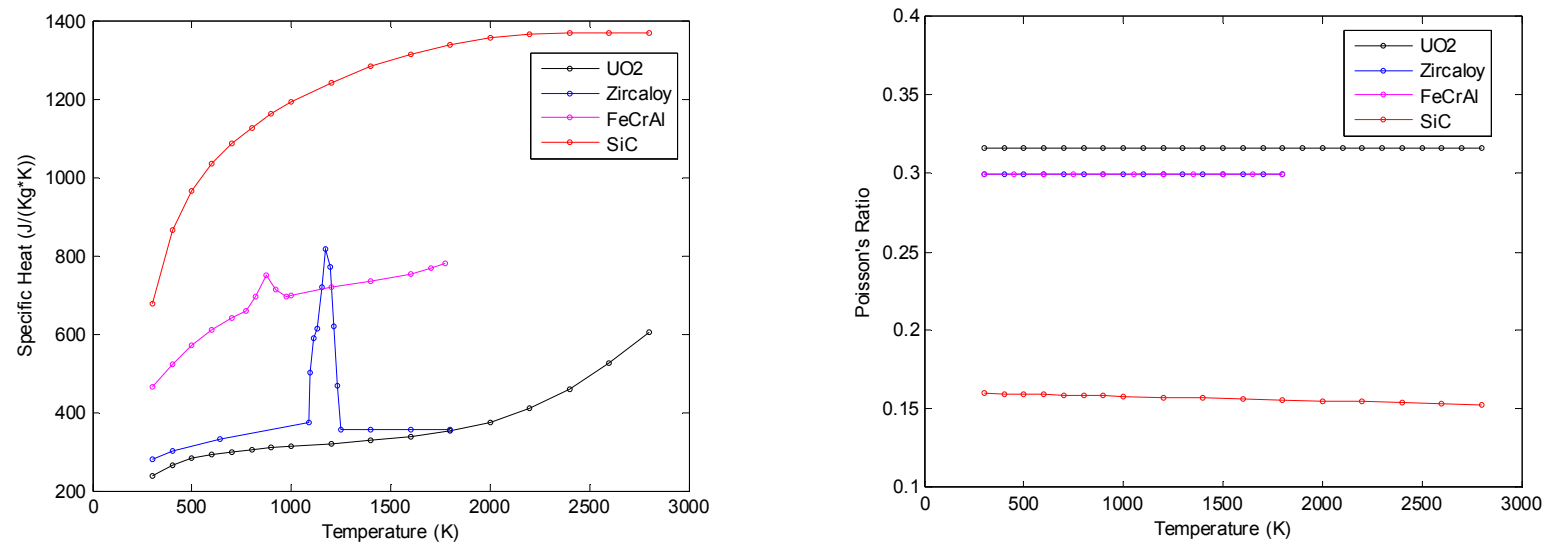

Figure 2. Specific heat capacity (left), Poisson's ratio (right).
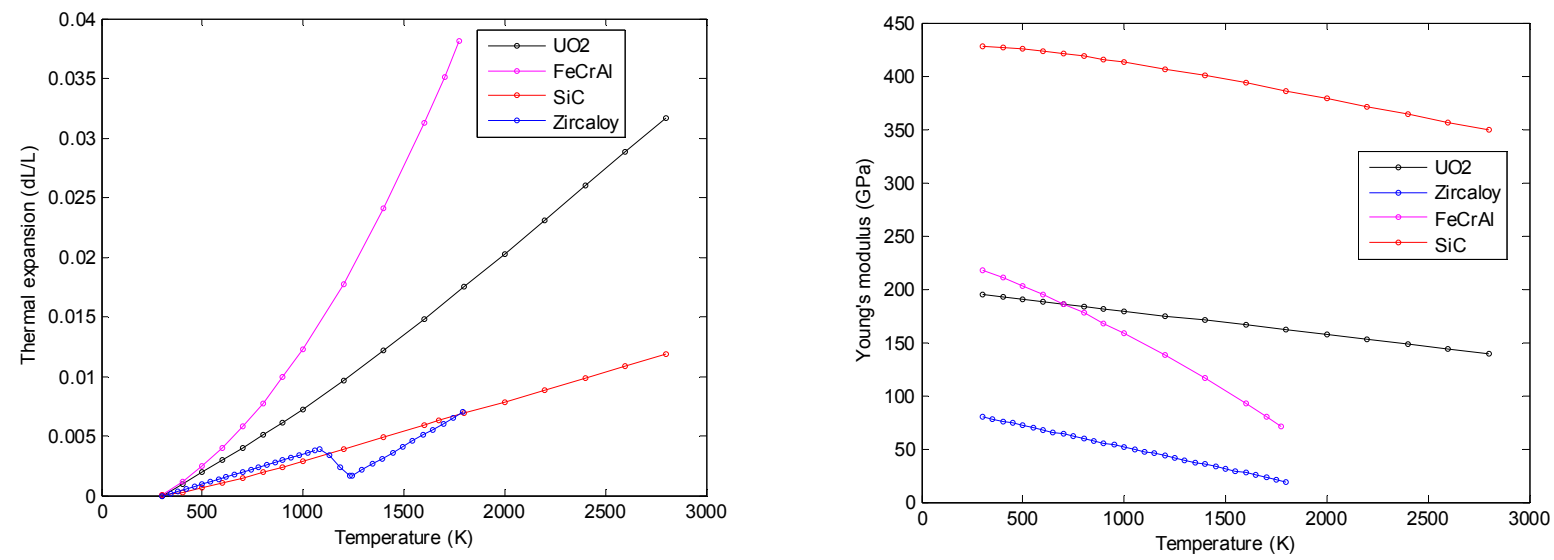

Figure 3. Thermal expansion (left), Young's modulus (right). 
For the specific heat capacity, the sharp spike for zircaloy is a result of a phase change (alpha to beta) from $1090 \mathrm{~K}$ to $1248 \mathrm{~K}$. Similarly, the peak around $800 \mathrm{~K}$ for $\mathrm{FeCrAl}$ is due to a magnetic phase transition [2]. The volumetric heat capacity and melting temperature could be found in Ott, Robb, and Wang's 2014 article [2].

Normally it is expected fuel and cladding with higher volumetric heat capacity will demonstrate a slower transient thermal response. Lower cladding thermal conductivity would lead to higher initial fuel rod temperatures and higher initial stored energy when LOCA begins [2]. However, slightly different results are found and will be presented in Section 5. The initial stored energy is not only dependent on thermal conductivity, but also on other material behaviors such as thermal and irradiation creep, as well as thermal expansion.

\section{MODEL FOR NEUTRONICS ANALYSIS}

In the first stage of the IRP-ATF, results of single assembly neutronics analysis were presented for selected coating materials applied to the surface of fuel cladding [10]. The selected materials were tested as coatings with 100 micron coating thickness. The reason for choosing the reactor physics analysis as the first stage is its magnitude should be quantified since neutron penalty is expected for the new candidate materials. Consequently, a possible solution for this reactivity loss could be increasing the fuel enrichment or reducing the cladding thickness. If the neutron penalty is too high, the viability for this material would be very low, and it would not be investigated further as a candidate material for cladding.

The single Pressurized Water Reactor (PWR) assembly for reactor physics analysis is the same as the one used in $\mathrm{Wu}$, Kozlowski, and Heuser's 2014 conference paper [10], and is briefly presented here. The assembly is based on the $17 \times 17$ Westinghouse design. Each assembly has 264 fuel pins and 25 guide tubes (here the central instrumentation tube is treated as a guide tube). The single assembly configuration is shown in Figure 4.

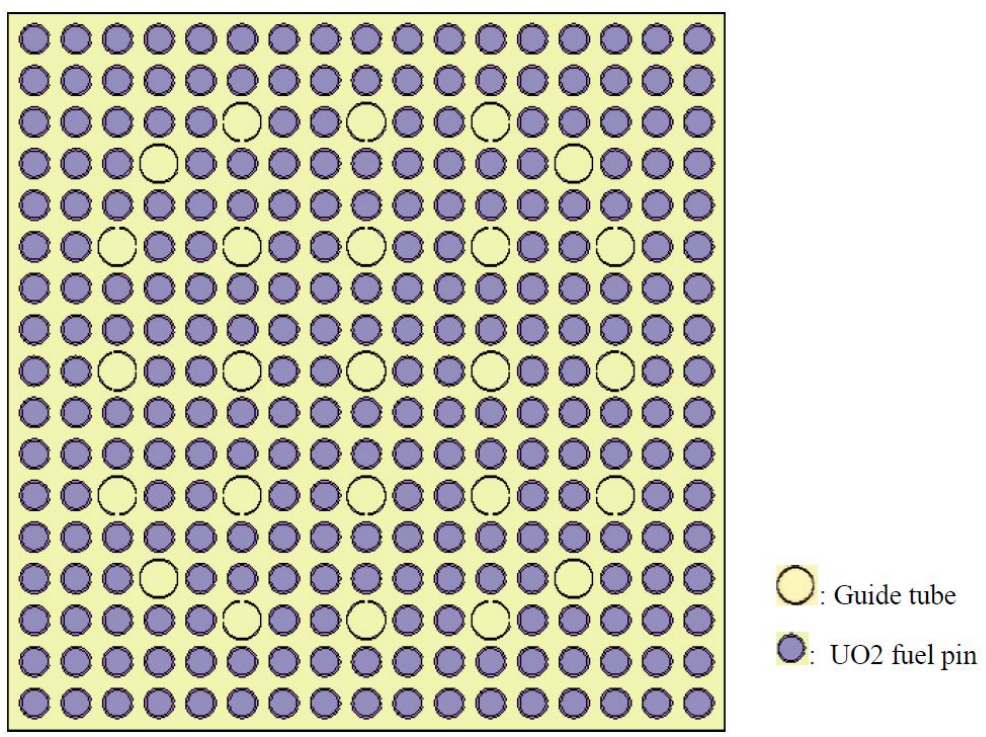

Figure 4. $\mathrm{UO}_{2} 4.2 \%$ fuel assembly.

The $\mathrm{UO}_{2}$ model is based on the $4.2 \% \mathrm{UO}_{2}$ assembly from the OECD/NEA and U.S. NRC PWR mixed oxide (MOX)/ $/ \mathrm{UO}_{2}$ core transient benchmark [15]. However, some modifications are adopted to simplify the model. Specifically, the Integral Fuel Burnable Absorber (IFBA) and Wet Annular Burnable Absorbers (WABA) pins are replaced by fuel pins and guide tubes, respectively. Also, the fuel rod gap is not considered, while the cladding thickness is preserved. Qualitatively similar results are observed for $\mathrm{UO}_{2}$ and MOX models, so only results based on the $\mathrm{UO}_{2}$ single assembly model are presented here. 
At the top and bottom of the single assemblies, $30 \mathrm{~cm}$ of coolant is added as an axial reflector. Table 1 shows the material composition used. The same type of Zircaloy- 2 material is used as cladding for the fuel pins and guide tubes. The assembly dimensions are summarized in Table 2.

Table 1. Material composition.

\begin{tabular}{|l|c|l|}
\hline \multicolumn{1}{|c|}{ Material } & $\begin{array}{c}\text { Density } \\
\left(\mathrm{g} / \mathrm{cm}^{3}\right)\end{array}$ & \multicolumn{1}{c|}{ Composition } \\
\hline $\mathrm{UO}_{2}$ & 10.24 & $\mathrm{U}-235: 4.2 \mathrm{wt} . \%, \mathrm{U}-238: 95.8 \mathrm{wt} . \%$ \\
\hline $\mathrm{Clad}$ & 6.504 & Zircaloy-2: $\mathrm{Zr} / \mathrm{Sn} / \mathrm{Fe} / \mathrm{Cr} / \mathrm{N}=98.23 / 1.50 / 0.12 / 0.10 / 0.05$ at. $\%$ \\
\hline Coolant & 0.75206 & Water at $560 \mathrm{~K}$ and $15.5 \mathrm{MPa}$ \\
\hline
\end{tabular}

Table 2. PWR single assembly dimensions.

\begin{tabular}{|l|c|}
\hline \multicolumn{1}{|c|}{$\begin{array}{c}\text { Dimensions } \\
(\mathrm{cm})\end{array}$} & Value \\
\hline Active fuel length & 365.7600 \\
\hline Assembly pitch & 21.4200 \\
\hline Pin pitch & 1.2600 \\
\hline Fuel rod cladding inner radius & 0.3951 \\
\hline Fuel rod cladding outer radius & 0.4583 \\
\hline Guide tube inner radius & 0.5624 \\
\hline Guide tube outer radius & 0.6032 \\
\hline
\end{tabular}

The original cladding thickness is 632 microns. To study the reactivity changes due to coatings, zircaloy cladding thickness is reduced to 532 microns, and coatings are applied with a thickness of 100 microns.

A three-dimensional (3-D) continuous-energy Monte Carlo reactor physics calculation code, Serpent, is used as the reactor neutronics code [16]. To achieve sufficiently high calculation precision, $200 \mathrm{~K}$ neutrons per cycle are used with 100 inactive cycles and 1,000 active cycles. This is sufficient to achieve eigenvalue statistical uncertainty of about $3 \mathrm{pcm}$.

\section{MODEL FOR FUEL PERFORMANCE ANALYSIS}

INL's finite element-based nuclear fuel performance code BISON [11] is used to model LWR nuclear fuel pin performance under normal operating conditions. BISON was built using MOOSE (Multiphysics Object Oriented Simulation Environment) [17]. MOOSE, which is a parallel computational framework designed for rapid production of new simulation tools, is also developed at INL.

\subsection{Material Models in BISON}

BISON solves the fully-coupled equations of thermo-mechanics and species diffusion, for either 1-D spherical, 2-D axisymmetric or 3-D geometries [13]. It incorporates a wide variety of material models for both fuel and zircaloy cladding. Temperature- and burnup-dependent thermal properties, as well as fission product swelling, densification, thermal and irradiation creep, fracture, and fission gas production and 
release are included for fuel models. For the cladding material, plasticity, irradiation growth, and thermal and irradiation creep models are implemented. Furthermore, BISON has models to simulate gas gap heat transfer, mechanical contact, and the evolution of the gap/plenum pressure with plenum volume, gas temperature, and fission gas addition. Detailed descriptions for all models and methods can be found in the BISON theory manual [13].

However, currently there is no oxidation model for FeCrAl. It is known from experiments the oxidation rate of $\mathrm{FeCrAl}$ is lower than that of zircaloy by at least two orders of magnitude [2]. Also, oxidation under normal operation is not as important as that in accident conditions such as LOCA. Therefore, oxidation rates were set to 0 for both $\mathrm{FeCrAl}$ and $\mathrm{SiC}$.

Another important issue is thermal and irradiation creep. BISON has irradiation creep for $\mathrm{SiC}$ [13]. It is also known that thermal creep for $\mathrm{SiC}$ is typically too small to be measured under $1670 \mathrm{~K}$ [18], which is much higher than the cladding temperature under normal operation. Therefore, here only the irradiation creep is considered for $\mathrm{SiC}$. For FeCrAl, neither thermal nor irradiation creep is currently available. Experimental tests are being carried out at ORNL and LANL to determine the creep behavior for FeCrAl. For the fuel performance analysis in BISON, one case is executed with no creep for FeCrAl, while in another case, zircaloy creep model is used for FeCrAl. These two cases could be used to bound the range of possible creep behavior of FeCrAl. This is a very optimistic estimate, since the creep for $\mathrm{FeCrAl}$ is assumed to be smaller than zircaloy in magnitude.

\subsection{LWR Fuel Pin Model in BISON}

The LWR fuel pin model used in BISON is shown in Figure 5. It includes the model configuration, power history, and operational parameters. It is based on the 2D-RZ example from the BISON workshop manual [19]. It is a well-established example and does not require excessive computational effort.

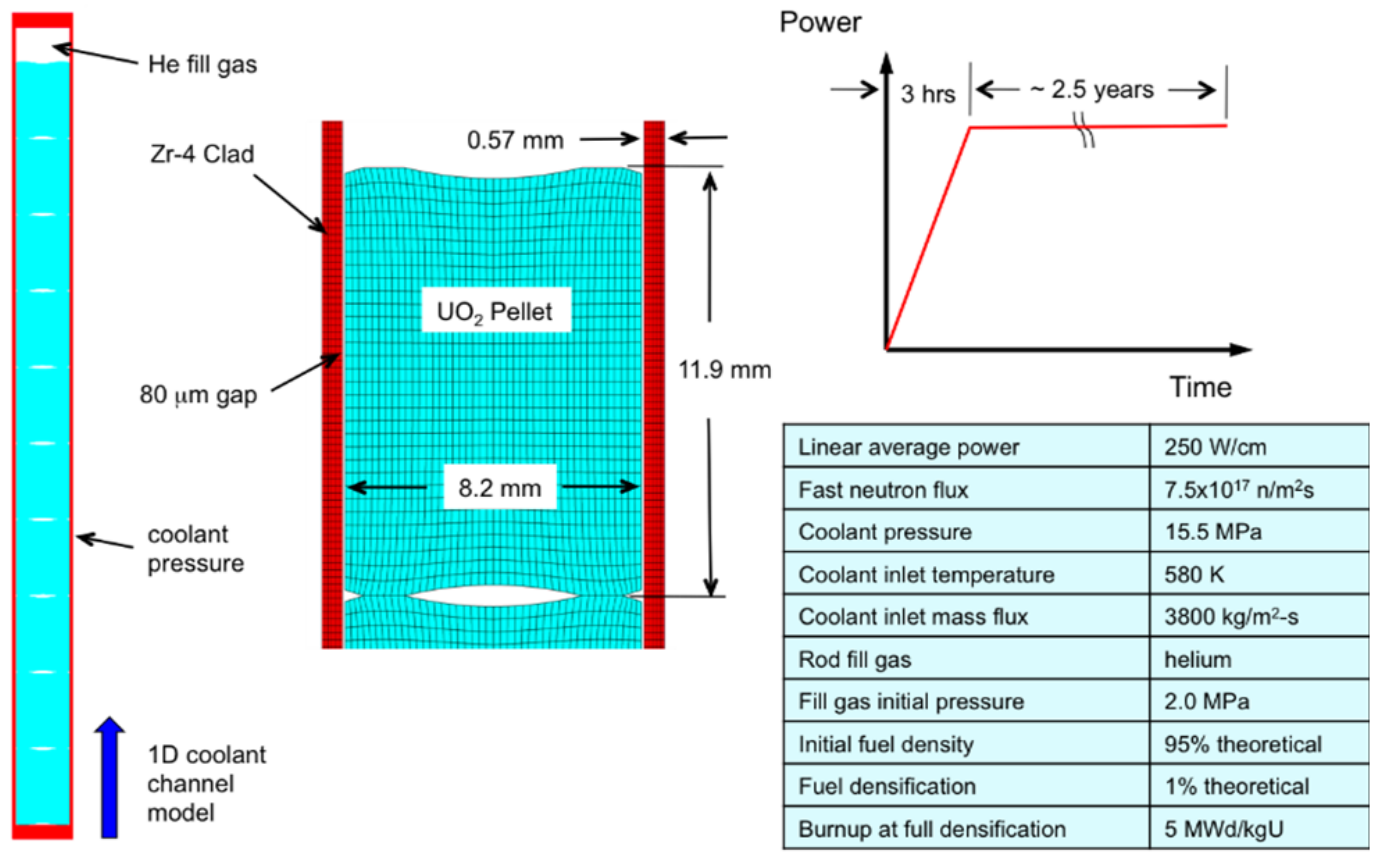

Figure 5. Ten pellet rodlet model [19].

\subsection{Mesh for Coating and Monolithic Cladding Cases}

Figure 6 shows the mesh for the monolithic cladding and coating (hybrid) cases. Linear quadrilateral elements are used here. 
The thickness for the original cladding is modeled as $0.56 \mathrm{~mm}(0.57 \mathrm{~mm}$ as shown in Figure 5, minus the gap width $0.08 \mathrm{~mm}$; however, $0.56 \mathrm{~mm}$ was used). The monolithic cladding cases include:

- $0.56 \mathrm{~mm}$ zircaloy

- $0.56 \mathrm{~mm} \mathrm{FeCrAl}$

- $0.56 \mathrm{~mm} \mathrm{SiC}$.

The coating (hybrid) cases include:

- $0.46 \mathrm{~mm}$ zircaloy $+0.1 \mathrm{~mm}$ FeCrAl

- $0.46 \mathrm{~mm}$ zircaloy $+0.1 \mathrm{~mm} \mathrm{SiC}$.
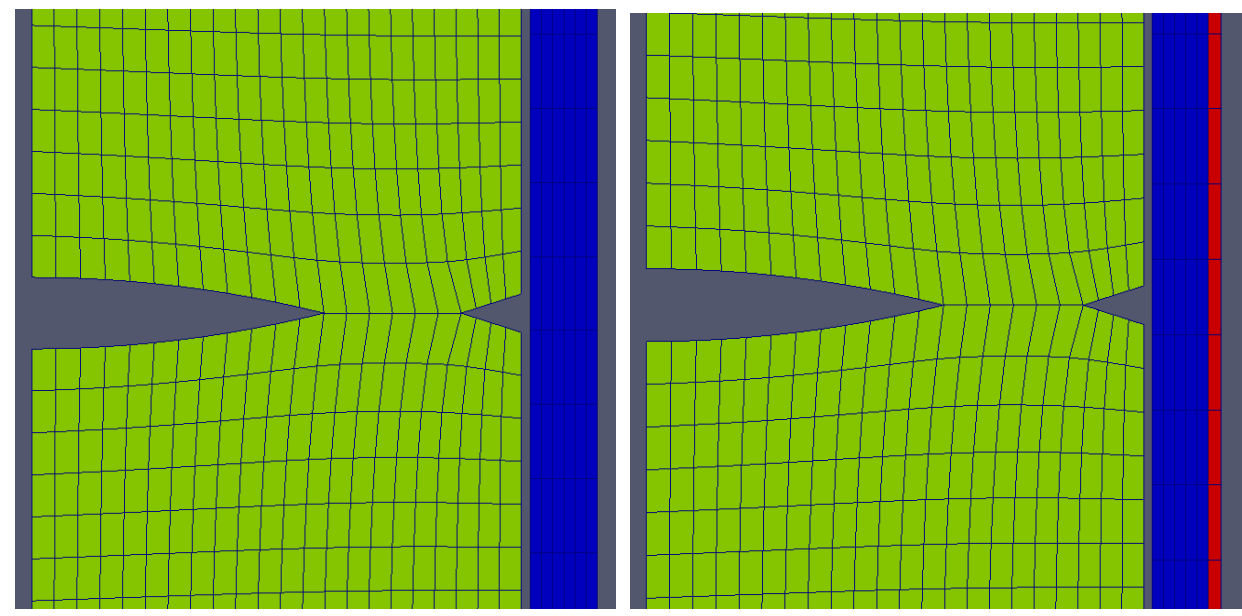

Figure 6. Mesh for monolithic cladding (left) and coating (right) cases.

\section{RESULTS AND DISCUSSION}

\subsection{Neutronics Evaluation}

Table 3 shows the effective multiplication factor for the selected PWR single assembly, without burnup. The burnup calculation results are illustrated in Figure 7.

Table 3. Comparison of effective multiplication factor $\mathrm{k}_{\mathrm{eff}}$ for PWR single assembly with various cladding material combinations.

\begin{tabular}{|l|c|}
\hline \multicolumn{1}{|c|}{ Cladding Cases } & $\begin{array}{c}\text { Multiplication Factor } \\
\text { (Serpent Library: ENDFB/VI.8) }\end{array}$ \\
\hline $0.56 \mathrm{~mm}$ zircaloy & 1.4263 \\
\hline $0.56 \mathrm{~mm} \mathrm{FeCrAl}$ & 1.2998 \\
\hline $0.46 \mathrm{~mm}$ zircaloy $+0.1 \mathrm{~mm} \mathrm{FeCrAl}$ & 1.4047 \\
\hline $0.56 \mathrm{~mm} \mathrm{SiC}$ & 1.4345 \\
\hline $0.46 \mathrm{~mm}$ zircaloy $+0.1 \mathrm{~mm} \mathrm{SiC}$ & 1.4274 \\
\hline
\end{tabular}




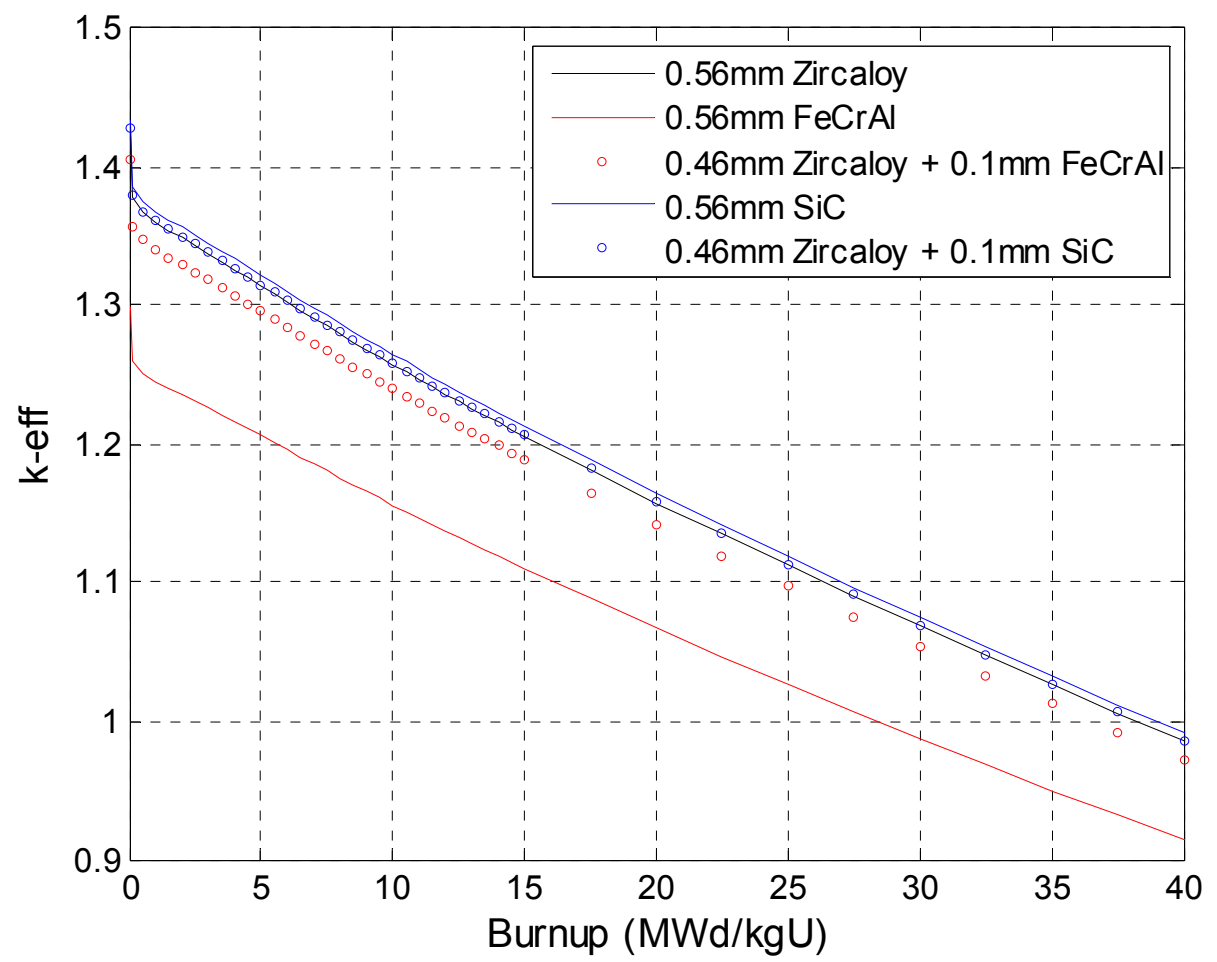

Figure 7. Comparison of $\mathrm{k}_{\mathrm{eff}}$ versus burnup for PWR single assembly, with various cladding material combinations.

Table 3 shows that FeCrAl has a considerable neutron penalty, especially when used as monolithic cladding. As mentioned earlier, this is because iron has a thermal neutron absorption cross-section that is about 12-16 times higher than that of zirconium. For $\mathrm{SiC}$, the $\mathrm{k}_{\text {eff }}$ increases due to its lower thermal neutron absorption cross-section, and carbon could serve as neutron moderator.

Assuming a constant axial power profile, the reduction in $\mathrm{k}_{\mathrm{eff}}$ leads to a significant drop in operational cycle length, as shown in Figure 7. Another reactor physics evaluation using SCALE shows SS-310 has an even more negative effect on neutronics than FeCrAl because of the presence of nickel [4]. Nickel's thermal neutron absorption cross-section is about twice that of iron. The cycle length is reported to be reduced by 198 days with the application of FeCrAl as monolithic cladding, and 273 days for SS-310.

According to Figure 7, choosing FeCrAl as monolithic cladding results in a loss of over 10 $\mathrm{MWd} / \mathrm{kgU}$ (198 days in cycle length as reported [4]). If FeCrAl is used as $0.1 \mathrm{~mm}$ coating, the loss in burnup is around $1.5 \mathrm{MWd} / \mathrm{kgU}$. On the contrary, the application of $\mathrm{SiC}$ will slightly increase the cycle length.

There are several possible ways to enhance the end-of-cycle reactivity and thus increase the cycle length for nuclear fuel with monolithic iron-based alloy cladding [4]:

1. Increase the oxide fuel enrichment. This would require about $1 \%$ increase in U-235 enrichment for monolithic iron-based alloy cladding.

2. Minimize the cladding thickness. The advanced iron-based alloys could enable fabrication of fuel cladding with thinner walls, because of their better strength, corrosion, and embrittlement properties.

3. Increase the mass of oxide fuel inside the nuclear reactor. Since cladding thickness could be reduced, if the volume of fuel pins is maintained, the extra space gained could be filled with oxide fuels. 
A good balance between options two and three above could be obtained: the cladding thickness is reduced to some extent and the additional space could accommodate extra fuel, with the enrichment maintained at the current value [4]. In the same reference, an evaluation of the economics of adopting iron-based alloys as monolithic cladding is provided. An increase in fuel costs between $15 \%-35 \%$ is expected. However, this does not account for the retooling cost for fuel and cladding fabrication. The overall increase in electricity cost is $4 \%-10 \%$.

Even though experimental investigation has proven iron-based alloys such as SS-310 and FeCrAl could have superior oxidation resistance under accident conditions, the cost is too high to use them as monolithic cladding. However, if $\mathrm{FeCrAl}$ is used as thin coating layer on the surface of zircaloy, the neutron penalty is greatly reduced and the additional cost is expected to reduce significantly. Moreover, $\mathrm{SiC}$ could result in extra reactivity, so the neutron penalty is not an issue.

\subsection{Fuel Performance Evaluation}

\subsubsection{Results for Monolithic Cladding Cases}

The end time for the BISON models is set to $10^{8}$ seconds, which is about 1,160 days (3.2 years). A uniform convective boundary at the clad outer wall is used to simulate heat transfer from the cladding surface to the coolant. The thermal-hydraulics model is simplified to a coolant channel, and details can be found in the BISON theory manual [13]. The rodlet model uses discrete pellets; a comparison of discrete pellets and smeared pellets may be found in Williamson, et al., 2012 [11].

Figure 8 shows fission gas release and plenum pressure over burnup. At each integration point, BISON computes the fission gas produced by a numerical time integration of the gas production rate, which is given as the product of fission rate and fractional yield of gas atoms per fission (with a value of 0.3017) [11]. Therefore, for all the cases, fission gas produced is the same as long as the power history is the same. The fission gas released is represented by the fraction of fission gas produced. Note that the $\mathrm{FeCrAl}$ case with creep is using the creep model from zircaloy.

To better interpret the above results, a brief description of the nominal fuel temperature evolution in a PWR fuel rod is provided as follows:

1. At the beginning of burnup, fuel densification leads to the increase of the gap, thus the heat conduction gets worse, and fuel temperature increases,

2. Fuel swelling and clad creep are combined to reduce gap size, which causes fuel temperature to decrease.

3. Fission gas release begins at a burnup of $20 \mathrm{MWd} / \mathrm{kgU}$. The mixing of fission gas with helium in the plenum decreases thermal conductivity of gap, and fuel temperature increases.

4. This temperature increase is gradually reversed by continuing gap closure, until the gap is fully closed at approximately $36 \mathrm{MWd} / \mathrm{kgU}$.

5. $\mathrm{UO}_{2}$ thermal conductivity decreases with burnup; therefore, fuel temperature increases.

Note the time scale mentioned above is for a nominal PWR core modeled by BISON, not for the rodlet used here. From the above five steps, it is obvious fuel temperature is affected by many factors, such as fuel densification, fuel swelling, cladding thermal and irradiation creep, cladding thermal expansion, and cladding thermal conductivity. Special attention should be paid to Step 3 because fission gas release and fuel temperature increase form a positive feedback over a long burnup period. High fuel temperature will cause more fission gas release, and with the exacerbation of the gap conductance caused by fission gas, fuel temperature will increase. This positive feedback will be most pronounced while the gap is open. 
Figure 9 shows the average internal temperature (average over fuel pellets and gap) and average cladding temperature over burnup. It is expect the higher volumetric heat capacity of cladding will introduce slower transient response [2]. This is generally true. But if we look at Figure 8 (left) and Figure 9 (left), the case of $\mathrm{SiC}$ as monolithic cladding has higher average internal temperature and more fission gas release at burnup below $35 \mathrm{MWd} / \mathrm{kgU}$. This is because thermal creep of $\mathrm{SiC}$ is negligible and irradiation creep of $\mathrm{SiC}$ is also very small compared to zircaloy. But when the gap is closed, the much higher thermal conductivity of $\mathrm{SiC}$ results in lower temperatures, and thus the average internal temperature is much lower than the other cases.

It is expected $\mathrm{FeCrAl}$ with no creep will have more fission gas release and higher average internal temperature. Since $\mathrm{FeCrAl}$ and zircaloy thermal conductivity are similar, and the $\mathrm{FeCrAl}$ case with creep uses the zircaloy creep model, those results are very similar.

Figure 8 (right) shows the plenum pressure. More fission gas release and higher internal temperature (similar to the $\mathrm{FeCrAl}$ case with no creep) should lead to a higher plenum pressure, but here we can see the zircaloy case and the $\mathrm{FeCrAl}$ case with creep have the highest plenum pressure. The reason for this can be found in Figure 10, which shows the fuel centerline temperature at the end of the simulation and clad interval volume over the burnup. The FeCrAl case with no creep and the $\mathrm{SiC}$ case have much higher interval volume, which explains their lower plenum pressure even though they have higher fission gas release.
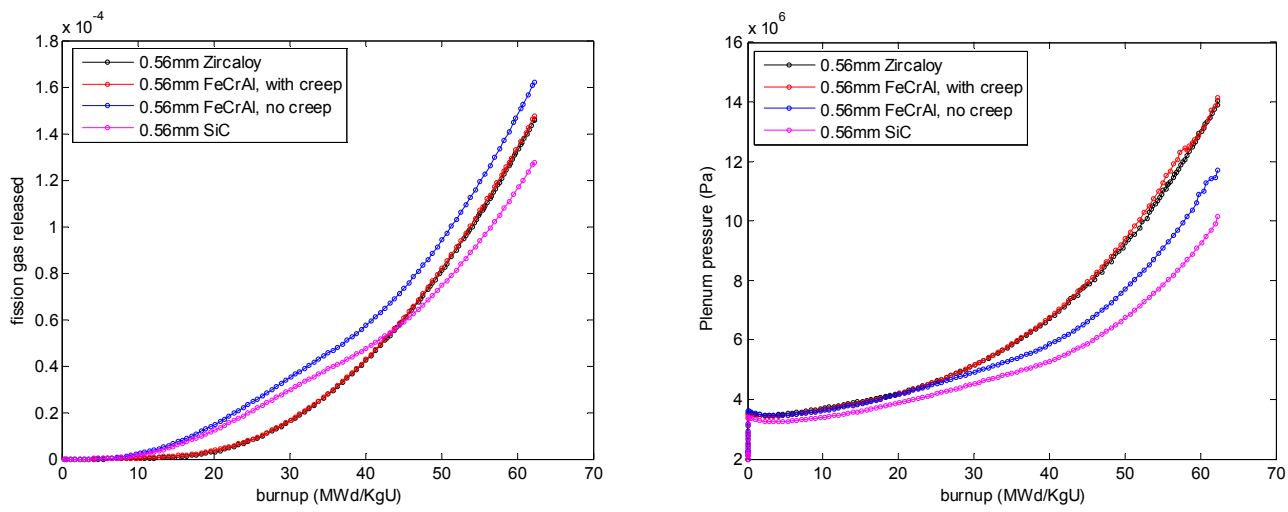

Figure 8. (Left) Fission gas released, (right) plenum pressure.
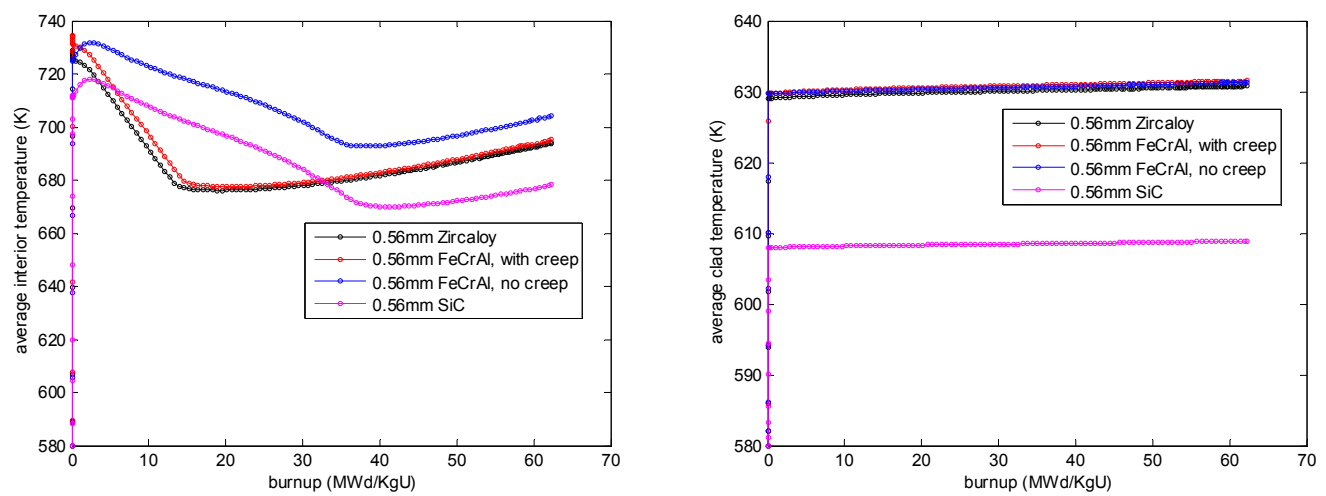

Figure 9. (Left) Average interior temperature, (right) average cladding temperature. 

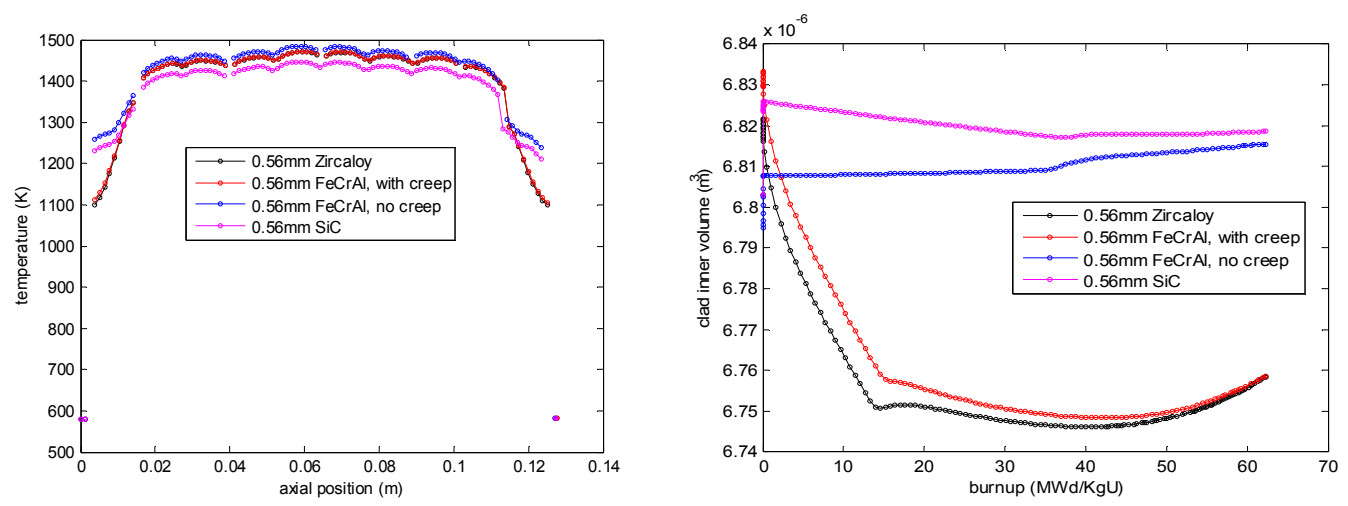

Figure 10. (Left) Temperature distribution over the fuel centerline at the end of simulation, (right) clad inner volume over the simulation.

Figure 10 (left) also shows the axial temperature profile is much flattened with the adoption of FeCrAl (because of no creep, the corresponding temperatures over the pellets serve as the upper bound in the figure) and $\mathrm{SiC}$ (because of high thermal conductivity, the corresponding temperatures over the pellets serve as the lower bound in the figure). Figure 11 shows the temperature and radial displacement for the horizontal line at the center of the fifth pellet from the bottom, at the end of simulation. It is noted that $\mathrm{SiC}$ cladding results in about $50 \mathrm{~K}$ decrease in the fuel centerline temperature, compared with other cases. Figure 11 (right) shows the radial displacements for the $\mathrm{SiC}$ case and $\mathrm{FeCrAl}$ case with no creep are much higher than the other two cases. This is expected behavior.
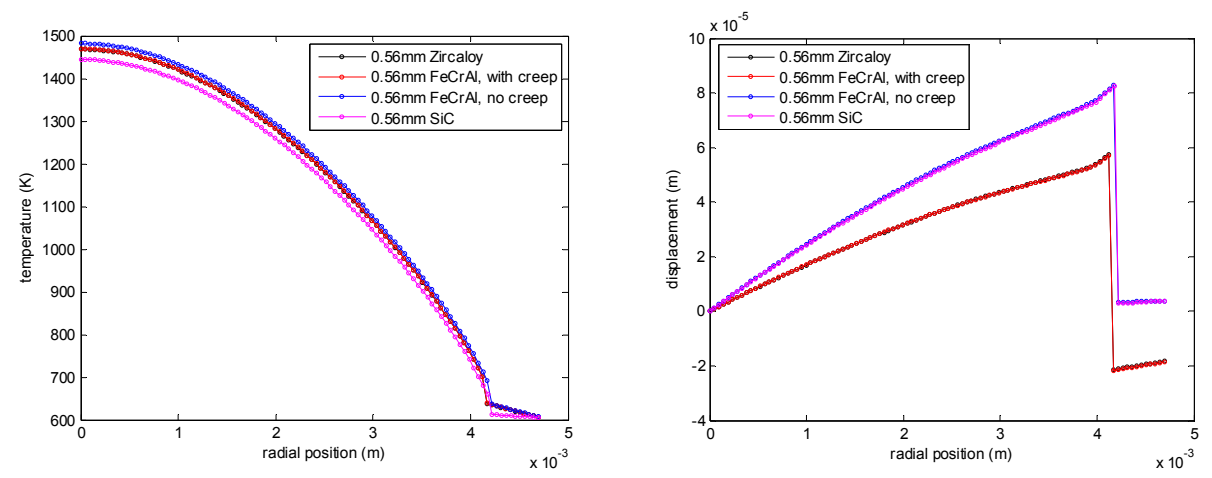

Figure 11. Plot over the horizontal center line of the fifth fuel pellet from bottom at the end of simulation (left), temperature distribution, (right) radial displacement distribution.

Figure 12 presents the gap sizes behavior of two nodes on the pellet surface. The left figure stands for the node at the height of $0.012 \mathrm{~m}$ (around center of the first pellet from bottom), and the right figure stands for the node at height of $0.07 \mathrm{~m}$ (center of the fifth pellet from bottom). It is summarized that:

1. At the beginning of simulation, gap width rapidly decreased from $0.08 \mathrm{~mm}$ to $0.03-0.04 \mathrm{~mm}$ as a combination of fuel densification, fuel thermal expansion, fuel swelling, cladding thermal creep, and cladding thermal expansion.

2. SiC case and $\mathrm{FeCrAl}$ case with no creep undergo a gap increase before 50 days because they have no cladding thermal creep.

3. Adoption of $\mathrm{SiC}$ and FeCrAl cladding (no creep) could greatly delay the gap closure by more than 400 days. This means Pellet-Cladding Mechanical Interaction (PCMI) is significantly delayed.

4. Gap closure occurs at very different time for different location in the fuel pins. 

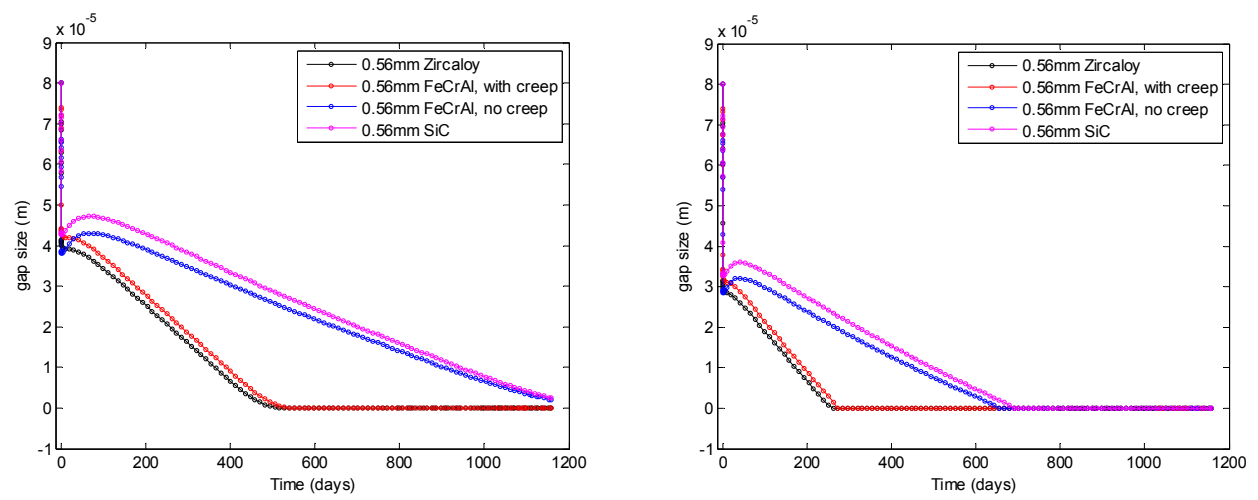

Figure 12. Plot of gap sizes for two nodes on fuel pellet surface, (left) at height of $0.012 \mathrm{~m}$, (right) at height of $0.07 \mathrm{~m}$.

\subsubsection{Results for Coating Layer Cases}

Figures 13 through 17 show the various results when $\mathrm{FeCrAl}$ and $\mathrm{SiC}$ are applied as coating layers instead of monolithic claddings. Qualitatively similar results are achieved compared with those in Section 5.3.1, but the discrepancies among different materials are reduced. This is expected since FeCrAl and $\mathrm{SiC}$ are only applied with a thickness of 100 microns. The reasons for differences and their physical mechanisms are the same as explained in the previous section.
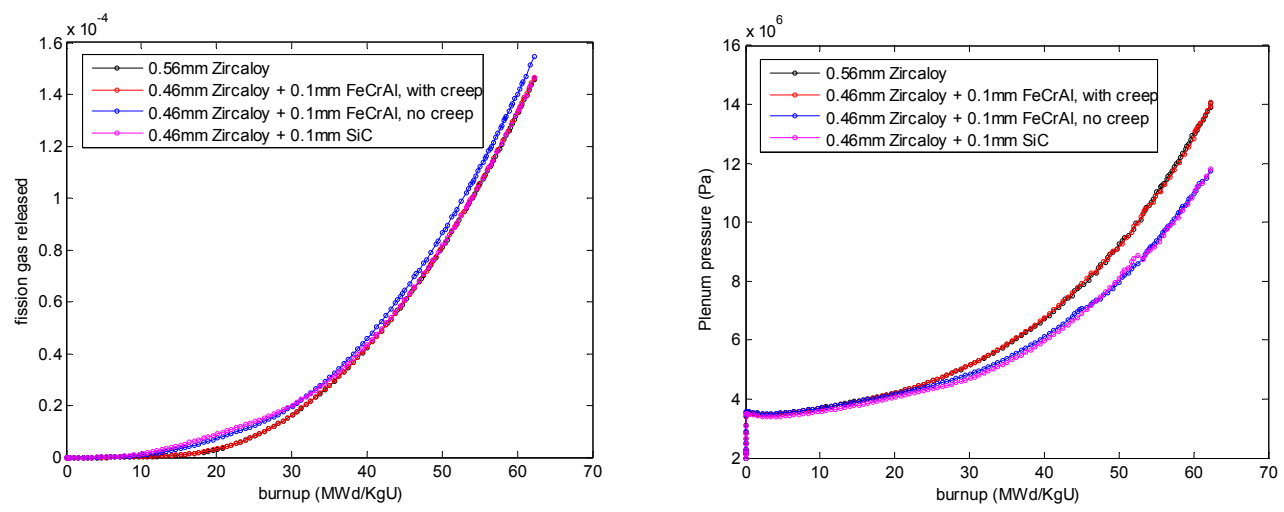

Figure 13. (Left) Fission gas released, (right) plenum pressure.
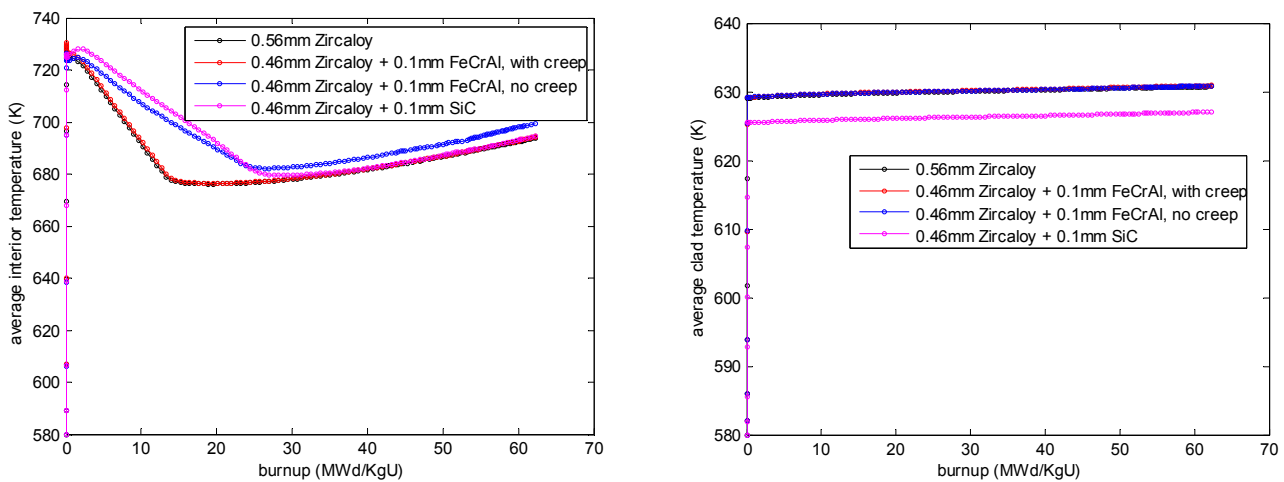

Figure 14. (Left) Average interior temperature, (right) average cladding temperature. 

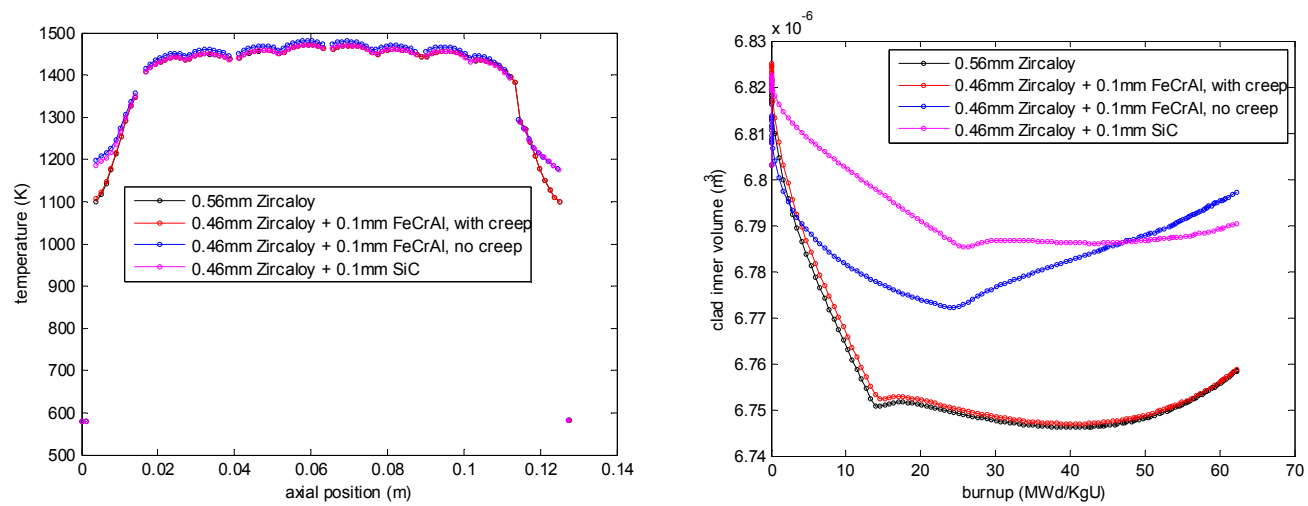

Figure 15. (Left) Temperature distribution over the fuel centerline at the end of simulation, (right) clad inner volume over the simulation.
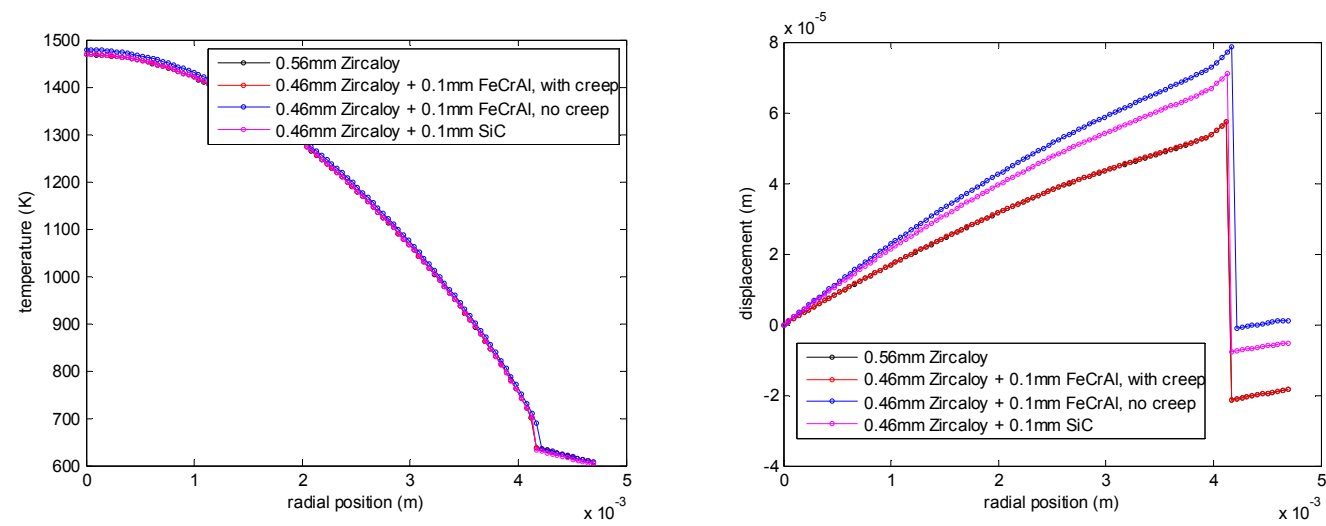

Figure 16. Plot over the horizontal center line of the fifth fuel pellet from bottom at the end of simulation, (left) temperature distribution, (right) radial displacement distribution.
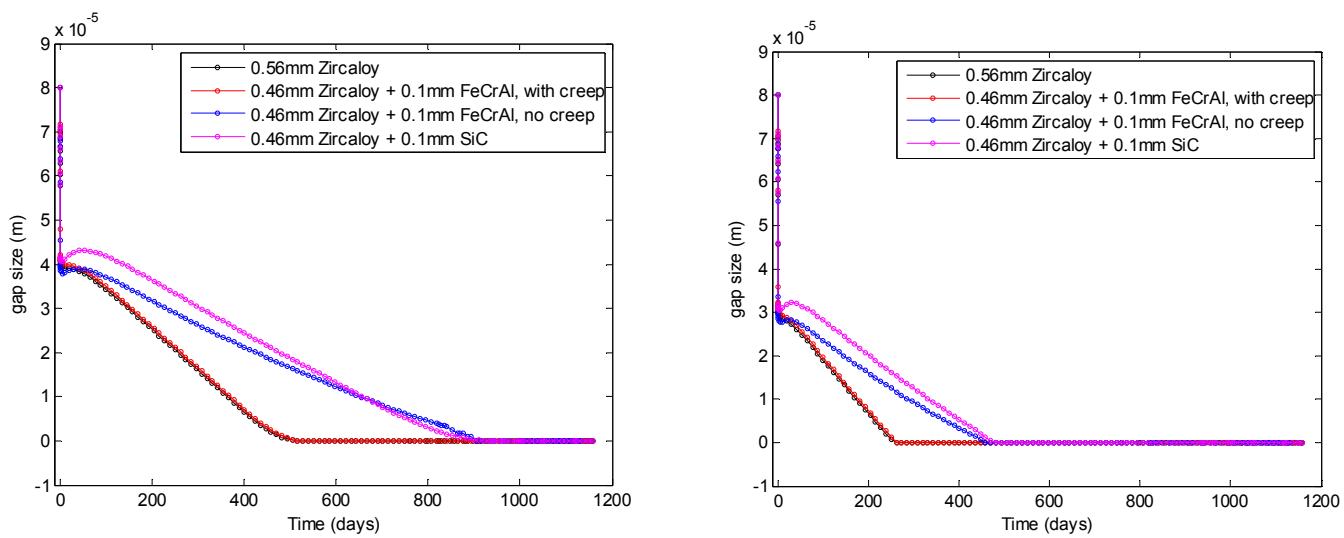

Figure 17. Plot of gap sizes for two nodes on fuel pellet surface, (left): at height of $0.012 \mathrm{~m}$, (right) at height of $0.07 \mathrm{~m}$. 


\subsection{Comparison of Zircaloy, FeCrAl, and SiC}

The excellent performance of $\mathrm{FeCrAl}$ alloy and $\mathrm{SiC}$ has already been validated in experimental investigation [3] [5] [6], [7], [14], [12] and system simulation using TRACE and MELCOR [2]. Also, a reactor physics and economics evaluation of ATF is provided in Terrani, Zinkle, and Snead's 2014 journal article [4]. Based on the results from Serpent and BISON presented in Sections 5.1 and 5.2, an evaluation of $\mathrm{FeCrAl}$ and $\mathrm{SiC}$ based on neutronics and fuel performance analysis will be discussed here, with the discussion of monolithic cladding compared to a coating layer presented in the next section.

From the neutronics standpoint:

1. Adoption of FeCrAl will have a considerable neutron penalty for nuclear reactors. A drop of 0.1265 in multiplication factor is expected if $\mathrm{FeCrAl}$ is used as a monolithic cladding and 0.0216 if it is used as a coating with thickness of 100 microns, for a Westinghouse-type 17 x 17 PWR single assembly.

2. Adoption of $\mathrm{SiC}$ as cladding will bring in positive reactivity.

From the fuel performance standpoint:

1. It is shown that higher thermal conductivity does not necessarily lead to lower fuel temperature and lower initial stored energy, unless the gap is closed. This is especially visible in SiC, whose thermal conductivity is more than three times larger than zircaloy at around $600 \mathrm{~K}$. Based on the simulation, $\mathrm{SiC}$ cladding results in higher fuel temperature at low-to-medium burnup (below $35 \mathrm{MWd} / \mathrm{kgU}$ ).

2. Creep, either caused by heat or irradiation, is proven to play an important role in the evolution of fuel temperatures. Creep of cladding could reduce gap and decrease fuel temperature over the burnup.

3. However, irradiation creep of zirconium is known to be a primary contributor to geometrical changes in fuel rods [20], which may not be desirable. For example, in a PWR reactor, permanent deformation of the fuel assemblies (like bowing) could lead to serious issues such as control rod drop failure or increased drop time, exacerbated local cooling, etc. Therefore, the low creep rate of $\mathrm{SiC}$ is expected to significantly reduce the fuel rod deformation, at the cost of $50 \mathrm{~K}$ higher fuel temperature.

4. Other impacts of using $\mathrm{FeCrAl}$ and $\mathrm{SiC}$ include reduced plenum pressure, flattened axial power profile, as well as very delayed gap closure time.

\subsection{Comparison of Monolithic Cladding and Coating}

The comparison of FeCrAl monolithic cladding and coating layer is summarized as follows:

1. For FeCrAl, the substantial drop in end-of-cycle reactivity limits its viability as a monolithic cladding. It could reduce the cycle length by about 200 days [4]. Compensating for the neutron penalty requires increasing U-235 enrichment by $1 \%$, or reducing the cladding thickness and increasing the fuel mass. Generally a significant increase in the fuel and electricity costs is expected.

2. Therefore, the most practical way of using FeCrAl in LWR fuel cladding is by applying it as a coating layer on the zircaloy surface (around 100 microns thick). The neutron penalty is acceptable, and its oxidation resistance would provide an increased margin of time for accident response and mitigation measures [2].

3. Highly adherent coating could avoid bulk compositional changes. Also, if a small portion of the coating spalls off during normal operation or handling, it could be easily regenerated [3].

4. Other major challenges to be considered with coating application are: (1) the thermal expansion of coating and cladding material should be carefully matched to avoid interfacial stresses; (2) neutron irradiation could cause coating spallation during normal operation, as the coating and cladding would undergo different volumetric and microstructural evolution [3]; (3) once the fuel rod bursts, the inner zircaloy surface would be exposed to steam under accident conditions, resulting in rapid oxidation, 
heat generation and hydrogen production; and (4) recently, it is reported SS-310 and FeCrAl could experience significant inter-diffusion with zirconium [12], which leads to an intermetallic layer with considerable thickness.

5. It is also suggested by ORNL researchers that applying $\mathrm{FeCrAl}$ on both the internal and external surfaces would provide protection against steam attack and spalling or corrosion issues [4], [12]. Nevertheless, they concluded monolithic FeCrAl cladding is expected to perform better under high-temperature steam environments in the absence of detrimental iron alloy-zirconium interactions [12].

Based on the evaluation above, moderate creep deformation (no bigger than zircaloy) and crack growth resistance is desired for $\mathrm{FeCrAl}$, in addition to its superior oxidation resistance. Furthermore, if the high-temperature strength of $\mathrm{FeCrAl}$ could be improved so spalling of the coating could be avoided, and inter-diffusion with zirconium could be minimized, it would be beneficial to use FeCrAl as a coating layer, considering the high fuel and electricity costs associated with using $\mathrm{FeCrAl}$ as monolithic cladding.

For $\mathrm{SiC}$, the simulation using BISON serves as a comparison for FeCrAl. It is very attractive for its excellent properties discussed earlier, but its application in a nuclear reactor is still limited. More engineering familiarity in the design and fabrication is required, as well as the test standards in nuclear applications. $\mathrm{SiC}$ is also known to be difficult to fabricate, and has low ductility compared with metallic cladding. Additionally, it is reported a thin $\mathrm{SiO}_{2}$ layer that forms on $\mathrm{SiC}$ could be less protective during LOCA, because when water vapor is presented, volatile hydroxides could form. These issues should be resolved before $\mathrm{SiC}$ finds application as nuclear fuel cladding.

\section{CONCLUSIONS}

Neutronics and fuel performance analysis were done for enhanced accident tolerance fuel, with the Monte Carlo reactor physics code Serpent and INL's fuel performance code BISON. The purpose is to evaluate two of the most promising candidate materials, $\mathrm{FeCrAl}$ and $\mathrm{SiC}$, as fuel cladding under normal operational conditions.

A substantial neutron penalty is identified when FeCrAl is used as monolithic cladding for current oxide fuel. To compensate for the drop in reactivity, several approaches are discussed in Section 5.1, including: (1) increasing the oxide fuel enrichment; (2) minimizing the cladding thickness to reduce the neutron penalty; and (3) reducing the cladding thickness and filling the extra volume with oxide fuel. Each of the approaches would substantially increase the fuel and electricity costs. Therefore, from the reactor physics standpoint, application of the FeCrAl alloy as a coating layer on surface of zircaloy cladding is a more practical method. Meanwhile, $\mathrm{SiC}$ increases reactivity, and the neutron penalty is of no concern.

Application of either $\mathrm{FeCrAl}$ or $\mathrm{SiC}$ could improve performance from the fuel performance standpoint. For example, the axial temperature profile is flattened. The gap closure time is significantly increased, which means the pellet-cladding mechanical interaction is greatly delayed. The disadvantages for the $\mathrm{SiC}$ and $\mathrm{FeCrAl}$ application are that: (1) fission gas release is increased; and (2) fuel temperature is higher at low to medium burnup, but it is less than a $50 \mathrm{~K}$ increase.

Detailed comparison between monolithic cladding and hybrid cladding (cladding + coating) is discussed. Hybrid cladding is more practical based on an economics evaluation during the transition from the current $\mathrm{UO}_{2}$ /zircaloy to ATF system. But a few issues remain to be resolved, such as the creep behavior of FeCrAl, coating spallation, and inter-diffusion with zirconium. For $\mathrm{SiC}$, its high thermal conductivity, excellent creep resistance, low thermal neutron absorption cross-section, and irradiation stability (negligible swelling) make it an excellent candidate material for future nuclear fuel/cladding research. 


\section{APPENDIX}

The material properties for $\mathrm{UO}_{2}$, zircaloy, $\mathrm{FeCrAl}$ and $\mathrm{SiC}$ used in this report are provided here. As is mentioned in section 2.3, most of the properties are the same as those used in Ott, Robb, and Wang's 2014 article [2], with minor differences in $\mathrm{UO}_{2}$ thermal conductivity. The symbols and units for the thermal-mechanical properties are summarized in Table 4.

Table 4. Comparison of effective multiplication factor keff for PWR single assembly with various cladding material combinations.

\begin{tabular}{|l|l|l|l|l|l|l|}
\hline Temperature & \multicolumn{1}{|c|}{ Density } & $\begin{array}{c}\text { Thermal } \\
\text { Conductivity }\end{array}$ & $\begin{array}{c}\text { Specific } \\
\text { Heat }\end{array}$ & $\begin{array}{c}\text { Thermal } \\
\text { Expansion }\end{array}$ & $\begin{array}{c}\text { Poisson's } \\
\text { Ratio }\end{array}$ & $\begin{array}{c}\text { Young's } \\
\text { Modulus }\end{array}$ \\
\hline$T$ & $\rho$ & $k$ & $c_{p}$ & $\Delta L / L$ & $v$ & $E$ \\
\hline$K$ & $\mathrm{~kg} / \mathrm{m}^{3}$ & $W /(m \cdot K)$ & $J /(\mathrm{kg} \cdot \mathrm{K})$ & unitless & unitless & $G P a$ \\
\hline
\end{tabular}

\section{$7.1 \mathrm{UO}_{2}$}

$\rho_{U O_{2}}=0.95 \times 10.98 \times\left[1.0-3.0 \times\left(\frac{\Delta L}{L(300 K)}\right)_{U O_{2}}\right] \quad 300 \mathrm{~K} \leq \mathrm{T} \leq 2800 \mathrm{~K}$

$\left(c_{p}\right)_{U_{2}}=296.7 \times\left(\frac{535.285}{T}\right)^{2} \times e^{\frac{535.285}{T}} /\left(e^{\frac{535.285}{T}}-1.0\right)^{2}+2.43 \times 10^{-2} \cdot T+$

$\left(1.65869 \times 10^{12}\right) * e^{\left(-1.8967 \times 10^{4} / T\right)} / T^{2} \quad 300 \mathrm{~K} \leq \mathrm{T} \leq 2800 \mathrm{~K}$

$\left(\frac{\Delta L}{L(300 K)}\right)_{U O_{2}}=-3.0 \times 10^{-3}+1.0 \times 10^{-5} \cdot \mathrm{T}+4.0 \times 10^{-2} \cdot \mathrm{e}^{5000.0 / \mathrm{T}} \quad 300 \mathrm{~K} \leq \mathrm{T} \leq 2800 \mathrm{~K}$

$v_{U O_{2}}=0.316$

$E_{U O_{2}}=201.2842 \times\left(1.0-1.0915 \times 10^{-4} \cdot \mathrm{T}\right) \quad 300 \mathrm{~K} \leq \mathrm{T} \leq 2800 \mathrm{~K}$

The thermal conductivity for $\mathrm{UO}_{2}$ is a complicated correlation called Fink-Lucuta model defined in Hales, et al. 2014 report [13].

$k_{U O_{2}}=k \cdot f_{d} \cdot f_{p} \cdot f_{p o r} \cdot f_{r} \quad 298 \mathrm{~K} \leq \mathrm{T} \leq 3120 \mathrm{~K}$

where:

$T_{n}=T / 1000, \mathrm{~T}$ is the temperature in $\mathrm{K}$ 
$k=\left(\frac{1}{7.5408+17.692 \cdot T_{n}+3.6142 \cdot T_{n}^{2}}+\frac{6400}{T_{n}^{2.5}} \exp \left(-\frac{16.35}{T_{n}}\right)\right) \cdot\left(\frac{1}{1-\left(2.6-0.5 \cdot T_{n}\right) \cdot 0.05}\right)$, which is the thermal conductivity at $100 \%$ theoretical density.

$f_{d}=\left(\frac{1.09}{b u^{3.265}}+0.0643 \cdot \sqrt{\frac{T}{b u}}\right) \cdot \arctan \left(\frac{1.0}{\frac{1.09}{b u^{3.265}}+0.0643 \cdot \sqrt{\frac{T}{b u}}}\right)$, which is the dissolved fission

products correction, $b u$ is the burnup in at.\%.

$f_{p}=1.0+\left(\frac{0.019 \cdot b u}{3.0-0.019 \cdot b u}\right) \cdot\left(\frac{1.0}{1.0+\exp \left(\frac{-(T-1200)}{100}\right)}\right)$, which is the precipitated fission products correction.

$f_{\text {por }}=\left(\frac{1.0-p}{1.0+0.5 \cdot p}\right)$, which is the porosity correction, $\mathrm{p}$ is the porosity.

$f_{r}=1.0-\frac{0.2}{1.0+\exp \left(\frac{T-900}{80}\right)}$, which is the radiation damage correction.

\subsection{Zircaloy}

$k_{Z r y}=7.511+2.088 \times 10^{-2} \cdot T-1.450 \times 10^{-5} \cdot T^{2}+7.668 \times 10^{-9} \cdot T^{3} \quad 300 \mathrm{~K} \leq \mathrm{T} \leq 1800 \mathrm{~K}$

$\left(\frac{\Delta L}{L(300 K)}\right)_{Z r y}= \begin{cases}4.95 \times 10^{-6} \cdot T-1.485 \times 10^{-3} & 300 \mathrm{~K} \leq \mathrm{T} \leq 1083 \mathrm{~K} \\ 2.77763 \times 10^{-3}+1.09822 \times 10^{-3} \cdot \cos \left(\pi \cdot \frac{T-1083}{161}\right) & 1083 \mathrm{~K} \leq \mathrm{T} \leq 1244 \mathrm{~K} \\ 9.7 \times 10^{-6} \cdot T-1.04 \times 10^{-2} & 1244 \mathrm{~K} \leq \mathrm{T} \leq 2098 \mathrm{~K}\end{cases}$

$v_{Z r y}=0.3$

$E_{Z r y}=92.1-4.05 \times 10^{-2} \cdot \mathrm{T} \quad 300 \mathrm{~K} \leq \mathrm{T} \leq 1800 \mathrm{~K}$

The material density and specific heat capacity for Zircaloy is provided in Table 5 . 
Table 5. Dependence of Zircaloy density and specific heat capacity on temperature for Zircaloy.

\begin{tabular}{|l|l|l|l|}
\hline Temperature & Density & Temperature & Specific heat \\
\hline 300 & 6551.38 & 300 & 281 \\
\hline 400 & 6539.685 & 400 & 302 \\
\hline 500 & 6528.032 & 640 & 331 \\
\hline 600 & 6516.42 & 1090 & 375 \\
\hline 700 & 6504.85 & 1093 & 502 \\
\hline 800 & 6493.32 & 1113 & 590 \\
\hline 900 & 6481.831 & 1133 & 615 \\
\hline 1000 & 6470.383 & 1153 & 719 \\
\hline 1073.15 & 6462.035 & 1173 & 816 \\
\hline 1074 & 6462.3 & 1193 & 770 \\
\hline 1200 & 6480.342 & 1213 & 619 \\
\hline 1273.15 & 6490.862 & 1233 & 469 \\
\hline 1274 & 6504.407 & 1248 & 356 \\
\hline 1400 & 6480.815 & 1400 & 356 \\
\hline 1600 & 6443.717 & 1600 & 356 \\
\hline 1800 & 6407.041 & 1800 & 356 \\
\hline
\end{tabular}

\subsection{FeCrAl}

$\rho_{\mathrm{FeCrAl}}=7.10-21.30 \times\left(-1.938 \times 10^{-3}+3.450 \times 10^{-6} \cdot T+1.080 \times 10^{-8} \cdot T^{2}\right) \quad 300 \mathrm{~K} \leq \mathrm{T} \leq 1773 \mathrm{~K}$

$k_{\mathrm{FeCrAl}}=2.53282+3.2532 \times 10^{-2} \cdot T-2.2 \times 10^{-5} \cdot T^{2}+8.5645 \times 10^{-9} \cdot T^{3} \quad 300 \mathrm{~K} \leq \mathrm{T} \leq 1773 \mathrm{~K}$

$\left(c_{p}\right)_{F e C r A l}= \begin{cases}220.6822+1.012945 \cdot T-7.19279 \times 10^{-4} \cdot T^{2}+1.84 \times 10^{-7} \cdot T^{3} & 300 \mathrm{~K} \leq \mathrm{T} \leq 773 \mathrm{~K} \\ 2145.283-4.43229 \cdot T+3.246312 \times 10^{-3} \cdot T^{2} & 773 \mathrm{~K} \leq \mathrm{T} \leq 873 \mathrm{~K} \\ 4083.095-6.74839 \cdot T+3.356712 \times 10^{-3} \cdot T^{2} & 873 \mathrm{~K} \leq \mathrm{T} \leq 973 \mathrm{~K} \\ 220.6822+1.012945 \cdot T-7.19279 \times 10^{-4} \cdot T^{2}+1.84 \times 10^{-7} \cdot T^{3} & 973 \mathrm{~K} \leq \mathrm{T} \leq 1773 \mathrm{~K}\end{cases}$

$\left(\frac{\Delta L}{L(293 K)}\right)_{F e C r A l}=-1.938 \times 10^{-3}+3.450 \times 10^{-6} \cdot T+1.080 \times 10^{-8} \cdot T^{2} \quad 300 \mathrm{~K} \leq \mathrm{T} \leq 1773 \mathrm{~K}$

$v_{\mathrm{FeCrAl}}=0.3$

$E_{\mathrm{FeCrAl}}=237.7808-6.041 \times 10^{-2} \cdot T-1.9 \times 10^{-5} \cdot T^{2} \quad 300 \mathrm{~K} \leq \mathrm{T} \leq 1773 \mathrm{~K}$ 


\section{$7.4 \quad$ SiC}

$\rho_{S i C}=3.215 \times\left[1.0-3.0 \times\left(\frac{\Delta L}{L(298 K)}\right)_{S i C}\right] \quad 300 \mathrm{~K} \leq \mathrm{T} \leq 2800 \mathrm{~K}$

$k_{S i C}=\left\{\begin{array}{l}194.776655-0.36061185 \cdot \mathrm{T}+3.3084327 \times 10^{-4} \cdot \mathrm{T}^{2}+ \\ -1.4600630 \times 10^{-7} \cdot \mathrm{T}^{3}+2.4758791 \times 10^{-11} \cdot \mathrm{T}^{4} \quad 200 \mathrm{~K} \leq \mathrm{T} \leq 1968 \mathrm{~K} \\ 24.96986 \quad 1968 \mathrm{~K} \leq \mathrm{T} \leq 2800 \mathrm{~K}\end{array}\right.$

$\left(c_{p}\right)_{S i C}=\left\{\begin{array}{l}925.65+0.3772 \cdot \mathrm{T}-7.9259 \times 10^{-5} \cdot \mathrm{T}^{2}-3.1946 \times 10^{7} \cdot \mathrm{T}^{-2} \quad 200 \mathrm{~K} \leq \mathrm{T} \leq 2400 \mathrm{~K} \\ 1365.54238+1.379 \times 10^{-3} \cdot \mathrm{T} \quad 2400 \mathrm{~K} \leq \mathrm{T} \leq 2800 \mathrm{~K}\end{array}\right.$

$\left(\frac{\Delta L}{L(298 K)}\right)_{S i C}=\left\{\begin{array}{cl}-1.1753 \times 10^{-4}-1.8276 \times 10^{-6} \cdot T+8.9 \times 10^{-9} \cdot T^{2}- & \\ 5.18133 \times 10^{-12} \cdot T^{3}+1.13115 \times 10^{-15} \cdot T^{4} & 300 \mathrm{~K} \leq \mathrm{T} \leq 1673 \mathrm{~K} \\ 4.26118 \times 10^{-3}+\left(4.9762791 \times 10^{-6} \cdot T-6.33555 \times 10^{-3}\right) & 1673 \mathrm{~K} \leq \mathrm{T} \leq 2800 \mathrm{~K}\end{array}\right.$

$v_{S i C}=0.160937533-2.84171929 \times 10^{-6} \cdot \mathrm{T} \quad 300 \mathrm{~K} \leq \mathrm{T} \leq 2800 \mathrm{~K}$

$E_{S i C}=428.3-0.04 \cdot \mathrm{T} \cdot \mathrm{e}^{-962.0 / \mathrm{T}} \quad 300 \mathrm{~K} \leq \mathrm{T} \leq 2800 \mathrm{~K}$ 


\section{REFERENCES}

[1] Goldner, F., "Development Strategy for Advanced LWR Fuels with Enhanced Accident Tolerance," Enhanced Accident Tolerant LWR Fuels National Metrics Workshop, Germantown, Maryland, October 2012.

[2] Ott, L. J., K. Robb, D. Wang, "Preliminary assessment of accident-tolerant fuels on LWR performance during normal operation and under DB and BDB accident condition," Journal of Nuclear Materials, 448.1, 2014, 520-533.

[3] Zinkle, S. J., K. Terrani, J. Gehin, L. Ott, L. Snead, "Accident tolerant fuels for LWRs: A perspective," Journal of Nuclear Materials, Vol. 448, No. 1, May 2014, pp. 374-379.

[4] Terrani, K. A., S. Zinkle, L. Snead, "Advanced oxidation-resistant iron-based alloys for LWR fuel cladding," Journal of Nuclear Materials, Vol. 448, No. 1, May 2014, pp. 420-435.

[5] Cheng, T., J. Keiser, M. Brady, K. Terrani, B. Pint, "Oxidation of fuel cladding candidate materials in steam environments at high temperature and pressure," Journal of Nuclear Materials, Vol. 427, No.1, August 2012, pp. 396-400.

[6] Yan, Y., J. Keiser, K. Terrani, G. Bell, L. Snead, "Post-quench ductility evaluation of Zircaloy-4 and select iron alloys under design basis and extended LOCA conditions," Journal of Nuclear Materials, Vol. 448, No. 1, May 2014, pp. 436-440.

[7] Pint, B. A., K. Terrani, M. Brady, T. Cheng, J. Keiser, "High temperature oxidation of fuel cladding candidate materials in steam-hydrogen environments," Journal of Nuclear Materials, Vol. 440, No. 1, September 2013, pp. 420-427.

[8] Snead, L. et al., "Fully ceramic microencapsulated fuel design and irradiation testing," OECD/NEA Workshop on Accident Tolerant Fuels for LWRs, NEA Headquarters, Issy-les-Moulineaux, France, December 2012.

[9] Heuser, B. J., T. Kozlowski, X. Wu, "Engineered Zircaloy Cladding Modifications for Improved Accident Tolerance of LWR Fuel: A Summary," Proc. of the 2013 LWR Fuel Performance Meeting/TopFuel, Charlotte, North Carolina, USA, September 15-19, 2013.

[10] Wu, X., T. Kozlowski, and B. Heuser, "Neutronics Analysis of Improved Accident Tolerance of LWR Fuel by Modifying Zircaloy Cladding of Fuel Pins," Proceedings of ICAPP-2014, Charlotte, USA, April 6-9, 2014.

[11] Williamson, R. L., J. Hales, S. Novascone, M. Tonks, D. Gaston, C. Permann, D. Andrs, R. Martineau, "Multidimensional multiphysics simulation of nuclear fuel behavior," Journal of Nuclear Materials, Vol. 423, No. 1, April 2012, pp. 149-163.

[12] Terrani, K. A., C. Parish, D. Shin, B. Pint, "Protection of zirconium by alumina-and chromia-forming iron alloys under high-temperature steam exposure," Journal of Nuclear Materials, Vol. 438, No. 1, July 2013, pp. 64-71.

[13] Hales, J. D., S. Novascone, G. Pastore, D. Perez, B. Spencer, R. Williamson, BISON Theory Manual: The Equations behind Nuclear Fuel Analysis, Fuels Modeling \& Simulation Department, Idaho National Laboratory, Idaho Falls, Idaho, June 2014. 
[14] Terrani, K. A., D. Wang, L. Ott, R. Montgomery, "The effect of fuel thermal conductivity on the behavior of LWR cores during loss-of-coolant accidents," Journal of Nuclear Materials, Vol. 448, No. 1, May 2014, pp. 512-519.

[15] Kozlowski T., and T. J. Downar, "OECD/NEA and US NRC PWR MOX/UO ${ }_{2}$ Core Transient Benchmark," Working Party of the Physics of Plutonium Fuels and Innovative Fuel Cycles, OECD/NEA Nuclear Science Committee, 2003.

[16] Leppänen, J., 2007, Development of a New Monte Carlo Reactor Physics Code, Ph.D. Thesis: VTT Technical Research Centre of Finland, Espoo, Finland.

[17] Gaston, D., C. Newman, G. Hansen, D. Lebrun-Grandie. "MOOSE: A parallel computational framework for coupled systems of nonlinear equations," Nuclear Engineering and Design, Vol. 239, No. 10, October 2009, pp. 1768-1778.

[18] Snead, L. L., T. Nozawa, Y. Katoh, T.-S. Byun, S. Kondo, D. Petti, "Handbook of SiC properties for fuel performance modeling," Journal of Nuclear Materials, Vol. 371, No. 1, September 2007, pp. 329-377.

[19] Williamson, R. L., et al. "Implicit, parallel, fully-coupled nuclear fuel performance analysis," Fuels Modeling \& Simulation Department BISON Workshop, Idaho National Laboratory, Idaho Falls, Idaho, June 2014.

[20] Yueh, K., and K. Terrani. "Silicon carbide composite for light water reactor fuel assembly applications," Journal of Nuclear Materials, Vol. 448, No., 1, May 2014, pp. 380-388. 